\title{
Lanthanide-doped near-infrared II luminescent nanoprobes for bioapplications
}

\author{
Shaohua $\mathrm{Yu}^{1,2}$, Datao $\mathrm{Tu}^{1 *}$, Wei Lian ${ }^{1,3}$, Jin $\mathrm{Xu}^{1}$ and Xueyuan Chen ${ }^{1,2,3^{*}}$
}

\begin{abstract}
Luminescent biosensing in the second nearinfrared (NIR-II) region is featured with superior spatial resolution and high penetration depth by virtue of the suppressed scattering of long-wavelength photons. Hitherto, the reported NIR-II nanoprobes are mostly based on carbon nanotubes, organic fluorophores or semiconducting quantum dots. As an alternative, trivalent lanthanide ions $\left(\mathrm{Ln}^{3+}\right)$ doped nanoparticles have been emerging as a novel class of promising nanoprobes. In this review, we highlight the recent progress in the design of highly efficient $\mathrm{Ln}^{3+}$-doped NIR-II nanoparticles towards their emerging bioapplications, with an emphasis on autofluorescence-free bioimaging, sensitive bioassay, and accurate temperature sensing. Moreover, some efforts and challenges towards this rapidly expanding field are envisioned.
\end{abstract}

Keywords: lanthanide ions, nanoprobe, near-infrared II luminescence, bioimaging, bioassay, temperature sensing

\section{INTRODUCTION}

Luminescent probes play a crucial role in numerous bioapplications including bioimaging, biodetection, as well as disease diagnosis and therapeutics [1-10]. Currently, the visible emitting probes are widely used for in vitro studies. Nevertheless, their applications in vivo are limited by the strong absorption and scattering of visible lights in the biological media [11-13]. To circumvent these restrictions, luminescent probes exhibiting emission between 1,000 and 1,700 nm within the second near-infrared (NIR-II) region have been emerging in recent years since they can dramatically reduce scattering lights and increase penetration depth in biological applications, compared with those emitting in the visible or the first
NIR (NIR-I, 750-1,000 $\mathrm{nm}$ ) regions [14-31].

To date, many advances have been made regarding the controlled synthesis, surface modification and optical properties of the NIR-II probes such as carbon nanotubes (CNTs) [32-36], organic fluorophores [37-39], semiconducting quantum dots (QDs) (e.g., PbSe and $\mathrm{Ag}_{2} \mathrm{~S}$ ) [40-42] and conjugated polymers [43]. However, CNTs usually exhibit broad emission bands $(>300 \mathrm{~nm}$ ) and low quantum yields (QY) (0.1-0.4\%), which impedes their practical applications. For organic fluorophores, they may suffer from photobleaching and poor photostability. Besides, there are some unavoidable drawbacks for QDs such as photoblinking or intrinsic toxicity from the heavy metal elements (e.g., $\mathrm{Pb}$ and $\mathrm{Cd}$ ). Conjugated polymers generally exhibit low solubility in aqueous solution. To these regards, it is of urgent demand to search for novel NIR-II luminescent nanoprobes to overcome the inherent limitations of the traditional ones.

Trivalent lanthanide ions $\left(\mathrm{Ln}^{3+}\right)$ have the electron configuration of $4 \mathrm{f}^{n} 5 \mathrm{~s}^{2} 5 \mathrm{p}^{6}(n=1-13)$. Due to the rich energy levels of $\mathrm{Ln}^{3+}$, their emissions cover the spectrum region from ultraviolet, visible to NIR. As an alternative to the traditional NIR-II probes, $\mathrm{Ln}^{3+}$-doped nanoparticles (NPs) are particularly intriguing owing to their superior properties, including high stability against photobleaching, long-lived ( $\mu \mathrm{s}-\mathrm{ms})$ luminescence for timegated detection, and narrow emission bands for multiplexed sensing [31,44-55]. All these features enable $\mathrm{Ln}^{3+}$ doped NIR-II NPs as an essential class of nanoprobes for diverse bioapplications. Several $\mathrm{Ln}^{3+}$ ions (e.g., $\mathrm{Yb}^{3+}$, $\mathrm{Tm}^{3+}, \mathrm{Er}^{3+}, \mathrm{Ho}^{3+}, \mathrm{Dy}^{3+}, \mathrm{Sm}^{3+}, \mathrm{Nd}^{3+}$ and $\mathrm{Pr}^{3+}$ ) were reported to produce NIR-II light (Fig. 1), but the NIR-II quantum yields (QYs) of most $\mathrm{Ln}^{3+}$-doped NPs were still

\footnotetext{
${ }^{1}$ CAS Key Laboratory of Design and Assembly of Functional Nanostructures, and Fujian Key Laboratory of Nanomaterials, Fujian Institute of Research on the Structure of Matter, Chinese Academy of Sciences, Fuzhou 350002, China

${ }^{2}$ University of Chinese Academy of Sciences, Beijing 100049, China

${ }^{3}$ College of Chemistry, Fuzhou University, Fuzhou 350116, China

* Corresponding authors (emails: dttu@fjirsm.ac.cn (Tu D); xchen@fjirsm.ac.cn (Chen X))
} 


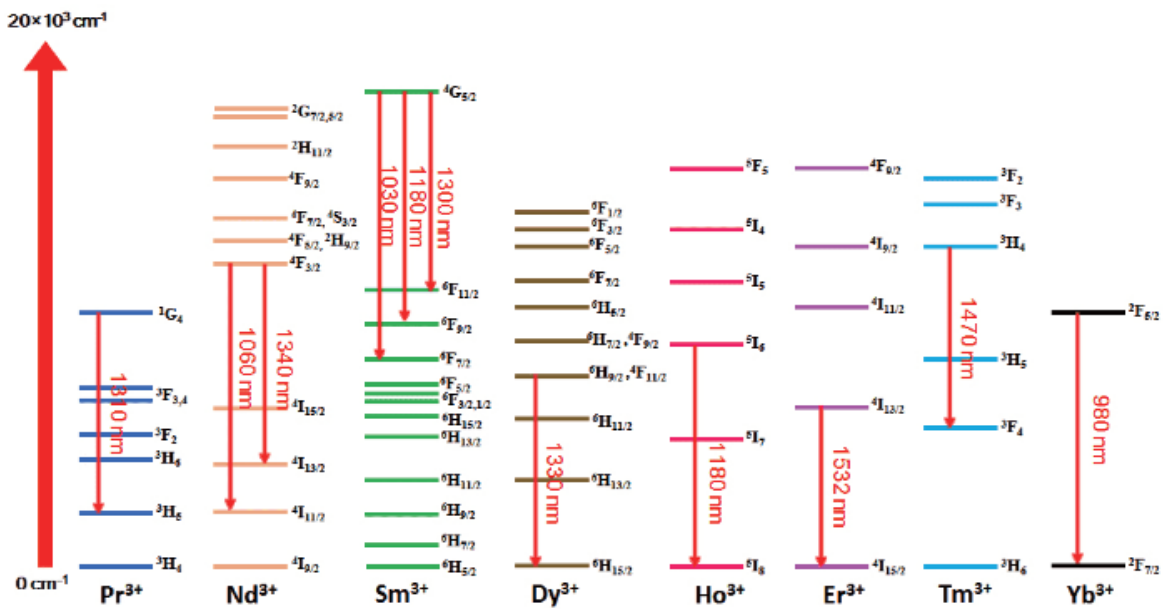

Figure 1 Energy level diagrams of $\operatorname{Ln}^{3+}$ ions with typical emissions within the NIR-II region.

too low to fulfill their practical application in luminescent biosensing. As such, continuous efforts were dedicated to developing highly efficient $\mathrm{Ln}^{3+}$-doped NIR-II luminescent nano-bioprobes.

Although several classes of NIR-II luminescent probes like organic fluorophores, CNTs and QDs have already been well summarized in academic journals or books [58-61], a review focusing on $\mathrm{Ln}^{3+}$-based NIR-II nanoprobes is highly desired so far. Rather than being exhaustive, this review aims to present a comprehensive investigation about the most recent achievements in $\mathrm{Ln}^{3+}$ doped nano-bioprobes, which mainly covers from the strategies for improving the photoluminescence (PL) efficiency to their promising applications (Fig. 2). We start by the design strategy of the highly efficient NIR-II NPs, with emphasis on host selection, cation incorporation and surface modification. We then highlight their key bioapplications such as bioimaging, bioassay and temperature sensing, respectively. Finally, emerging trends and further efforts are proposed.

\section{DESIGN OF HIGHLY EFFICIENT NIR-II NANOPROBES}

One of the bottlenecks for practical applications of NIR-II luminescent probes lies in their low QYs, which is defined as the ratio of the number of emitted photons to that of the absorbed photons. QYs of typical $\mathrm{Ln}^{3+}$-doped NIR-II NPs are summarized in Table 1 , which indicates that most of them show low PL efficiency. In order to achieve high NIR-II luminescence output for commercial applications, researchers proposed several strategies such as host selection, cation incorporation, and surface mod-

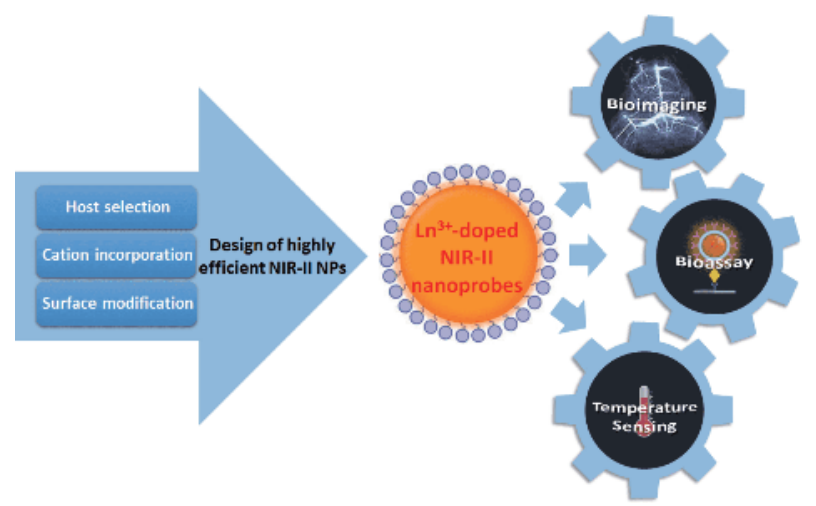

Figure 2 Overview of $\mathrm{Ln}^{3+}$-doped NIR-II nanoprobes from design strategies to bioapplications.

ification.

\section{Host selection}

The PL efficiency of $\mathrm{Ln}^{3+}$ relies critically on the structure, crystal fields, local site symmetry and phonon energy of the host materials $[45,50]$. Thus, the selection of hosts determines the optical properties of the $\mathrm{Ln}^{3+}$ dopants. Generally, desirable host materials should possess high optical damage threshold, low phonon energy, and close lattice matches to $\mathrm{Ln}^{3+}$ dopants. Among these features, the phonon energy is a key parameter influencing their QYs. The host matrix with low energy phonons may suppress the multi-phonon relaxation process and reduce the non-radiative energy losses. This is important for $\mathrm{Ln}^{3+}$ ions emitting in the NIR-II region, since the NIR-II emissions are easily quenched by high-energy vibrations [65]. Therefore, halide hosts (e.g., $\mathrm{LiYF}_{4}$ [8], $\mathrm{CaF}_{2}$ [63], 
Table 1 Optical characteristics and QYs of typical $\mathrm{Ln}^{3+}$-doped NIR-II NPs

\begin{tabular}{|c|c|c|c|c|c|}
\hline Nanoprobe & Size $(\mathrm{nm})$ & Excitation $(\mathrm{nm})$ & Emission (nm) & QY (\%) & Reference \\
\hline $\mathrm{LiYF}_{4}: \mathrm{Nd}$ & $18 \times 25$ & 808 & $900 / 1050$ & 28 & {$[8]$} \\
\hline $\mathrm{NaYF}_{4}: \mathrm{Yb} / \mathrm{Er}$ & $183 \times 113$ & 975 & 1525 & 0.2 & {$[44]$} \\
\hline $\mathrm{NaGdF}_{4}: \mathrm{Nd} / \mathrm{Yb} / \mathrm{Tm}$ & 21 & 800 & $980 / 1060$ & 1.06 & {$[56]$} \\
\hline $\mathrm{NaCeF}_{4}: \mathrm{Er} / \mathrm{Yb}$ & 200.6 & 980 & 1530 & 32.8 & {$[57]$} \\
\hline $\mathrm{NaNdF}_{4}: \mathrm{Mn}$ & 4.5 & 808 & 1058 & 10 & {$[62]$} \\
\hline $\mathrm{CaF}_{2}: \mathrm{Y} / \mathrm{Nd}$ & $10-15$ & 808 & $989 / 1056 / 1328$ & 9.3 & {$[63]$} \\
\hline $\mathrm{NaGdF}_{4}: \mathrm{Nd} @ \mathrm{NaGdF}_{4}$ & 15 & 740 & $900 / 1050 / 1330$ & 40 & {$[64]$} \\
\hline $\mathrm{NaYF}_{4}: \mathrm{Yb} / \mathrm{Er} @ \mathrm{NaLuF}_{4}$ & 26.2 & 980 & 1522 & 14 & {$[66]$} \\
\hline $\mathrm{NaYbF}_{4}: \mathrm{Er} / \mathrm{Ce} @ \mathrm{NaYF}_{4}$ & 18 & 980 & 1550 & $0.27-2.73$ & {$[67]$} \\
\hline $\mathrm{NaYF}_{4}: \mathrm{Yb} / \mathrm{Nd} @ \mathrm{CaF}_{2}$ & 13 & 800 & $980 / 1060$ & $\sim 11$ & {$[68]$} \\
\hline $\mathrm{NaYF}_{4}: \mathrm{Yb} / \mathrm{Nd} @ \mathrm{CaF}_{2}$ & 12 & 808 & 980 & 20.7 & {$[69]$} \\
\hline $\begin{array}{c}\mathrm{NaYF}_{4}: \mathrm{Yb} / \mathrm{Er} @ \mathrm{NaYbF}_{4} @ \\
\mathrm{NaYF}_{4}: \mathrm{Nd} @ \mathrm{ICG}\end{array}$ & 52 & 800 & $1000 / 1064 / 1530$ & 13.2 & {$[70]$} \\
\hline $\mathrm{NaYF}_{4}: \mathrm{Er} @ \mathrm{ICG}$ & $\sim 17$ & 808 & 1520 & 3.1 & {$[72]$} \\
\hline $\mathrm{CsPbCl} \mathrm{Pb}_{3}: \mathrm{Yb}$ & 16 & 380 & 980 & 170 & {$[75]$} \\
\hline $\mathrm{CsPbCl}_{1.5} \mathrm{Br}_{1.5}: \mathrm{Yb} / \mathrm{Ce}$ & 6.9 & 365 & 980 & 119 & {$[77]$} \\
\hline InP@YF $:{\mathrm{Yb} @ L u F_{3}}$ & 10 & 440 & 980 & 0.5 & {$[79]$} \\
\hline
\end{tabular}

$\mathrm{NaYF}_{4}$ [44], $\mathrm{NaGdF}_{4}$ [64], $\mathrm{LaF}_{3}$ [71] and $\mathrm{SrF}_{2}$ [28]) with high chemical stability and low phonon energies are often selected as host matrix for the doping of $\mathrm{Ln}^{3+}$ ions to achieve bright NIR-II emissions.

Because of the parity-forbidden nature of $f-f$ transitions of $\mathrm{Ln}^{3+}$ ions, the direct excitation for most $\mathrm{Ln}^{3+}$ is usually inefficient. To overcome this, the strategy of sensitization of $\mathrm{Ln}^{3+}$ ions by hosts like semiconductor NPs was proposed to enhance the absorption of excitation light $[73,74]$. As a consequence, the NIR-II luminescence of $\mathrm{Ln}^{3+}$ is expected to be greatly enhanced via an efficient energy transfer from the semiconductor host to the doped $\mathrm{Ln}^{3+}$ ions. Chen and co-workers reported the efficiently host-sensitized NIR-II emissions of $\mathrm{Nd}^{3+}$ or $\mathrm{Er}^{3+}$ ions doped in a series of semiconductor NPs such as $\operatorname{In}_{2} \mathrm{O}_{3}$ [76], $\mathrm{SnO}_{2}$ [78], $\mathrm{TiO}_{2}$ [80] and $\mathrm{ZnO}[81,82]$. To exemplify this, $\mathrm{Er}^{3+}$ ions were doped into the lattice of $\mathrm{SnO}_{2} \mathrm{NPs}$, which gave rise to NIR-II emissions of $\mathrm{Er}^{3+}$ at $1.55 \mu \mathrm{m}$ upon excitation above the $\mathrm{SnO}_{2}$ bandgap (Fig. 3a). By monitoring the emission of $\mathrm{Er}^{3+}$, the PL excitation spectrum was dominated by an intense and broad band centered at $300 \mathrm{~nm}$ that corresponds to the bandgap absorption of $\mathrm{SnO}_{2}$ NPs (Fig. 3b). Meanwhile, the emission spectrum displayed sharp NIR emission lines originating from the ${ }^{4} \mathrm{I}_{13 / 2} \rightarrow{ }^{4} \mathrm{I}_{15 / 2}$ transition of $\mathrm{Er}^{3+}$ ions upon excitation at $300 \mathrm{~nm}$, verifying the efficient energy transfer from $\mathrm{SnO}_{2}$ host to emitters ( $\mathrm{Er}^{3+}$ ions).

Recently, semiconducting QDs are also employed to overcome the weak absorption of $\mathrm{Ln}^{3+}$ ions for improving their PL efficiency, because QDs have strong broadband absorption and tunable bandgap. However, the synthesis of $\mathrm{Ln}^{3+}$-doped QDs remains a great challenge. In one of the earliest reports, $\mathrm{Yb}^{3+}$ was doped in CdSe QDs through a three-step synthesis strategy [83]. However, only weak emission of $\mathrm{Yb}^{3+}$ was achieved upon excitation above the CdSe bandgap at $580 \mathrm{~nm}$. Due to the large absorption cross-section of perovskite QDs, much effort was recently devoted to introducing $\mathrm{Ln}^{3+}$ ions into $\mathrm{CsPbX}_{3}$ perovskite QDs (e.g., $\mathrm{CsPbCl}_{3}$ [75], $\mathrm{CsPbBr}_{3}$ [84,85], $\mathrm{CsPbI}_{3}$ [85], $\left.\mathrm{CsPbCl}_{1.5} \mathrm{Br}_{1.5}[77,86]\right)$ in order to realize strong NIR emission of $\mathrm{Yb}^{3+}$. The NIR luminescent QY for $\mathrm{CsPbCl}_{3}$ : $\mathrm{Yb}$ NPs was reported to be as high as $170 \%$ upon excitation at $380 \mathrm{~nm}$ [75]. In addition to $\mathrm{Ln}^{3+}$-doped QDs, core/shell structures were fabricated for the sensitization of $\mathrm{Ln}^{3+}$ ions. Alivisatos and co-workers [79] designed $\mathrm{InP} / \mathrm{Ln}_{x} \mathrm{Y}_{1-x} \mathrm{~F}_{3} / \mathrm{ShF}_{3} \quad(\mathrm{Ln}=\mathrm{Yb} / \mathrm{Nd}, \quad \mathrm{Sh}=\mathrm{Lu} / \mathrm{Y}) \quad$ core/shell/ shell NPs to realize the broad excitation of $\mathrm{Yb}^{3+}$ via the sensitization of InP.

\section{Cation incorporation}

Intentional cation incorporation is an effective way to manipulate the optical properties of $\mathrm{Ln}^{3+}$-doped NPs by either controlling the energy transfer process or altering the crystal field and the local site symmetry of $\mathrm{Ln}^{3+}$ ions.

Some cations (e.g., $\mathrm{Ln}^{3+}$ or transition metal ions) were usually chosen as "energy donor" ions by virtue of their 

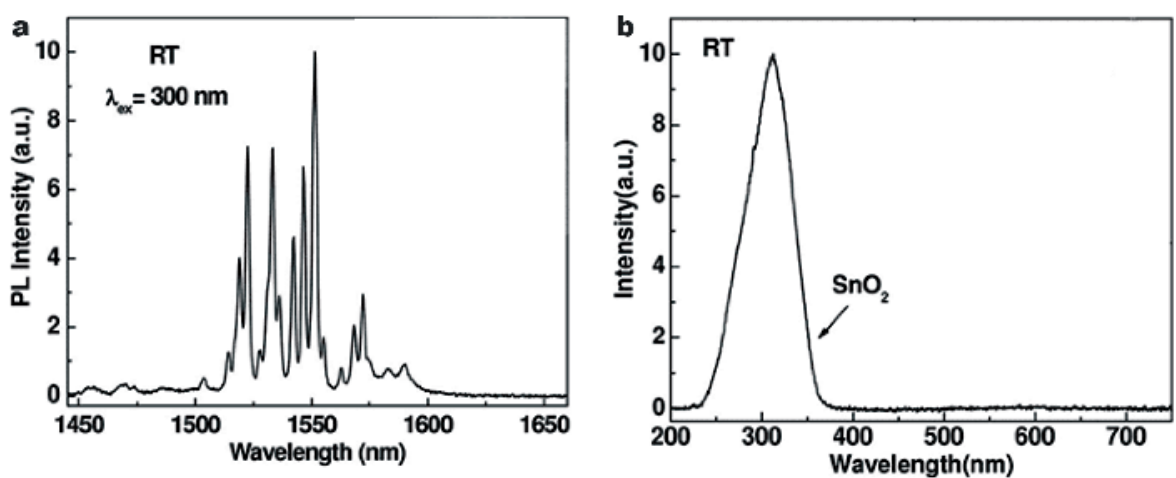

Figure 3 (a) Emission spectrum of $\mathrm{SnO}_{2}$ :Er NPs upon excitation at $300 \mathrm{~nm}$. (b) Excitation spectrum of $\mathrm{SnO}_{2}$ :Er NPs by monitoring the emission at 1,551.2 nm. Adapted with permission from Ref. [78]. Copyright 2009, Optical Society of America.

relatively large absorption cross section. For instance, $\mathrm{Yb}^{3+}$ or $\mathrm{Nd}^{3+}$ ions are widely doped as sensitizers to harvest the NIR excitation photons (980 or $808 \mathrm{~nm}$ ) and transfer the energy to $\mathrm{Ln}^{3+}$ emitters [46,73]. $\mathrm{Er}^{3+}$ or $\mathrm{Ho}^{3+}$ ions were also reported to serve as sensitizers to harvest the excitation lights of 1,532 and $1,150 \mathrm{~nm}$, respectively [87-89]. For transition metal ions, $\mathrm{Bi}^{3+}$ was co-doped with $\mathrm{Yb}^{3+}$ in $\mathrm{Gd}_{2} \mathrm{O}_{3}$ NPs to enhance the NIR-II emission of $\mathrm{Yb}^{3+}$ via cooperative energy transfer under broad-band ultraviolet excitation (250-400 nm) of $\mathrm{Bi}^{3+}$ [90].

Besides sensitization, cation incorporation may also act as a bridge for energy transfer. The co-doping of $\mathrm{Ce}^{3+}$ with $\mathrm{Er}^{3+}$ and $\mathrm{Yb}^{3+}$ ions enhanced the NIR-II emission of $\mathrm{Er}^{3+}[57,67,91]$. High QY of $\mathrm{Er}^{3+}$ (i.e., $0.27-2.73 \%$ ) was achieved for $\mathrm{NaYbF}_{4}: \mathrm{Er} / \mathrm{Ce} @ \mathrm{NaYF}_{4}$ core/shell NPs in aqueous solutions [67]. In these NPs, the upconversion (UC) pathway of $\mathrm{Er}^{3+}$ was suppressed while the downshifting (DS) emission of $\mathrm{Er}^{3+}$ at 1,550 $\mathrm{nm}$ was boosted by $\sim 9$ times. Similar phenomenon was observed by Chen and co-workers in $\mathrm{NaCeF}_{4}: \mathrm{Er} / \mathrm{Yb} \mathrm{NPs}$ [57]. The ${ }^{4} \mathrm{I}_{13 / 2}$ state of $\mathrm{Er}^{3+}$ can be markedly populated through the efficient phonon-assisted non-radiative relaxation from the ${ }^{4} \mathrm{I}_{11 / 2}$ state facilitated by $\mathrm{Ce}^{3+}$ ions, due to small energy mismatch between ${ }^{2} \mathrm{~F}_{5 / 2} \rightarrow{ }^{2} \mathrm{~F}_{7 / 2}$ of $\mathrm{Ce}^{3+}\left(\sim 2,300 \mathrm{~cm}^{-1}\right)$ and ${ }^{4} \mathrm{I}_{11 / 2} \rightarrow{ }^{4} \mathrm{I}_{13 / 2}$ of $\mathrm{Er}^{3+}\left(\sim 3,700 \mathrm{~cm}^{-1}\right) . \mathrm{Gd}^{3+}$ was also reported to serve as the intermediate bridge ions to promote the energy transfer from the accumulator ions to $\mathrm{Ln}^{3+}$ ions. For example, an efficient energy transfer pathway of $\mathrm{Nd}^{3+}$ $\rightarrow \mathrm{Yb}^{3+} \rightarrow \mathrm{Tm}^{3+} \rightarrow \mathrm{Gd}^{3+} \rightarrow \mathrm{Nd}^{3+}$ in $\mathrm{NaGdF}_{4}: \mathrm{Nd} / \mathrm{Yb} / \mathrm{Tm} \mathrm{NPs}$ was proposed by Chaudhuri and co-workers [56]. In the $\mathrm{NaGdF}_{4}: \mathrm{Nd} / \mathrm{Yb} / \mathrm{Tm}$ NPs, $\mathrm{Gd}^{3+}$ served as a bridge to transfer the energy from ${ }^{1} \mathrm{I}_{6}$ of $\mathrm{Tm}^{3+}$ to ${ }^{2} \mathrm{P}_{1 / 2}$ of $\mathrm{Nd}^{3+}$, followed by a non-radiative relaxation to the ${ }^{4} \mathrm{~F}_{3 / 2}$ and ${ }^{4} G_{7 / 2}$ multiplets, resulting in the intense NIR-II emission of $\mathrm{Nd}^{3+}$ (Fig. 4a). Significantly enhanced NIR-II emission intensity of $\mathrm{Nd}^{3+}$ by $\sim 3$ times was realized as compared with that of $\mathrm{Gd}^{3+}$-free counterparts (i.e., $\mathrm{NaYF}_{4}: \mathrm{Nd} / \mathrm{Yb} / \mathrm{Tm} \mathrm{NPs}$ ) under otherwise identical conditions (Fig. 4b).

Additionally, co-doping with $\mathrm{Y}^{3+}$ ions was reported to enhance the NIR-II emission intensity of $\mathrm{Nd}^{3+}$ by Quintanilla and co-workers [92]. In their work, the addition of $\mathrm{Y}^{3+}$ ions into the $\mathrm{CaF}_{2}$ host avoided clustering and PL quenching of $\mathrm{Nd}^{3+}$ ions. Similarly, Zhang and co-workers adopted the same strategy to improve the PL efficiency of $\mathrm{CaF}_{2}: \mathrm{Nd} \mathrm{NPs}$ by co-doping with $\mathrm{Y}^{3+}$ [63]. As a result, a high NIR-II QY of 9.30\% was achieved, which was $\sim 3$ times higher than that of $\mathrm{CaF}_{2}: \mathrm{Nd} \mathrm{NPs}$.

\section{Surface modification}

The deleterious surface quenching effect in the colloidal dispersions deriving from their high surface area-to-volume ratio of NPs strongly affects the QY of $\mathrm{Ln}^{3+}$-doped NPs. To minimize the PL quenching of emitters from the surface ligands and liquid media, designing high-quality core/shell structure is frequently used $[93,94]$. For example, silica shell coating was adopted to suppress the vibrational quenching caused by the $\mathrm{O}-\mathrm{H}$ groups $[64,95]$. As a result, the NIR-II emission intensity of $\mathrm{Ln}^{3+}$ dopants in the core NPs can be increased. Moreover, it was found that surface passivation by growing a uniform shell with similar lattice parameters was more efficient to improve the NIR-II QY of $\mathrm{Ln}^{3+}$-doped NPs. For instance, the NIRII emission intensity of $\mathrm{NaGdF}_{4}: \mathrm{Nd} \mathrm{NPs}$ was increased by 1.82 times after coating with a $2-\mathrm{nm} \mathrm{NaGdF}_{4}$ shell [64]. The NIR-II QY of $\mathrm{Nd}^{3+}$ in these $\mathrm{NaGdF}_{4}: \mathrm{Nd} @ \mathrm{NaGdF}_{4}$ core/shell NPs was as high as $40 \%$. Likewise, the NIR-II emission intensity of $\mathrm{NaYF}_{4}: \mathrm{Yb} / \mathrm{Nd}$ core NPs was enhanced by 45 times after coating with the $\mathrm{CaF}_{2}$ shell [68]. Recently, Alivisatos and co-workers [66] investigated the 

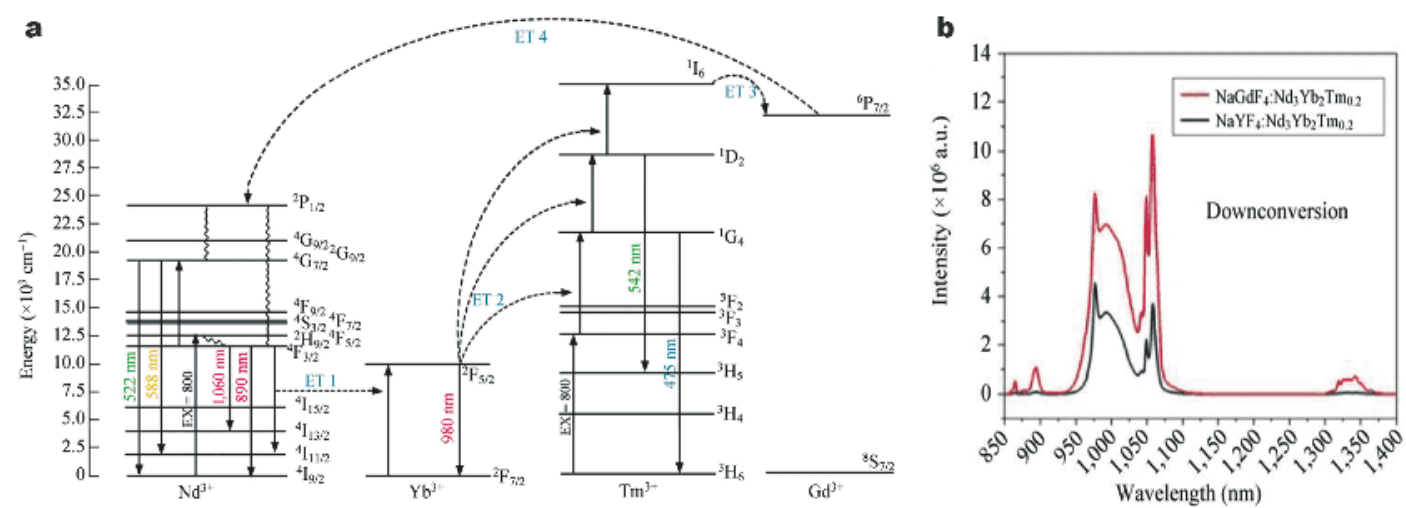

Figure 4 (a) Scheme illustration of the energy transfer between $\mathrm{Nd}^{3+}, \mathrm{Yb}^{3+}, \mathrm{Tm}^{3+}$ and $\mathrm{Gd}^{3+}$ in $\mathrm{NaGdF}$ : $\mathrm{Nd} / \mathrm{Yb} / \mathrm{Tm} \mathrm{NPs}$. $(\mathrm{b}) \mathrm{NIR}$ emission spectra of $\mathrm{NaGdF}_{4}: \mathrm{Nd} / \mathrm{Yb} / \mathrm{Tm}$ and $\mathrm{NaYF}_{4}: \mathrm{Nd} / \mathrm{Yb} / \mathrm{Tm}$, respectively. Adapted with permission from Ref. [56]. Copyright 2014, Tsinghua University Press and Springer-Verlag GmbH Germany, part of Springer Nature.

relationship between shell thickness and the NIR-II emission intensity of $\mathrm{Er}^{3+}$ in $\mathrm{NaYF}_{4}: \mathrm{Yb} / \mathrm{Er} @ \mathrm{NaYF}_{4}$ core/ shell NPs. They demonstrated that surface quenching assisted downshifting (SQAD) processes increased the population of ${ }^{4} \mathrm{I}_{13 / 2} \mathrm{Er}^{3+}$ energy level in thin shelled NPs due to energy transfer from ${ }^{4} \mathrm{I}_{11 / 2}$ of $\mathrm{Er}^{3+}$ or ${ }^{4} \mathrm{~F}_{5 / 2}$ of $\mathrm{Yb}^{3+}$ to ${ }^{4} \mathrm{I}_{13 / 2}$ of $\mathrm{Er}^{3+}$ (Fig. 5a). The NIR-II QY of $\mathrm{Er}^{3+}$ decreased markedly in $\mathrm{NaYF}_{4}: \mathrm{Yb} / \mathrm{Er} @ \mathrm{NaYF}_{4} \mathrm{NPs}$ with very thick shells where the SQAD processes were suppressed. Thus, as shown in Fig. 5b, there existed an optimized shell thickness $(2.4 \mathrm{~nm})$ for the highest NIR-II QY of $\mathrm{Er}^{3+}$. In comparison with the NIR-II QY of $\mathrm{Er}^{3+}$, the UC QY of $\mathrm{Er}^{3+}$ gradually increased and reached a stable plateau when the thickness of the shell was above $\sim 5 \mathrm{~nm}$.

Besides coating with an inorganic shell, surface modification with organic molecules (e.g., tropolonate, indocyanine green) was also adopted for the efficient NIR-
II emission of $\operatorname{Ln}^{3+}[70,96]$. As a typical example, indocyanine green (ICG) was coated on the surface of $\mathrm{NaYF}_{4}: \mathrm{Yb} / \mathrm{X} @ \mathrm{NaYbF}_{4} @ \mathrm{NaYF}_{4}: \mathrm{Nd}(\mathrm{X}=\mathrm{Er}, \mathrm{Ho}, \mathrm{Tm}$, or Pr) NPs to increase their NIR-II emission intensity [70]. In the ICG sensitized core-shell-shell (CSS) NPs, the energy transfer efficiency from ICG to the NPs was $\sim 75 \%$. Meanwhile, their NIR-II QY was $\sim 13 \%$. Note that the layer of organic molecule may passivate the surface of $\mathrm{Ln}^{3+}$-doped NPs and endow them with water solubility when they are transferred from a hydrophobic environment to hydrophilic one $[8,69,73]$. Such a feature is particularly important for NIR-II emissions of $\mathrm{Ln}^{3+}$ which is sensitive to aqueous media due to small energy gap between their excited and ground states $[45,65]$. To this end, several ligands like poly(acrylic acid) [73,97], polyethyleneimine [44], poly(maleic anhydride-alt-1-octadecene)-polyethylene glycol (PMH-PEG) [67] were
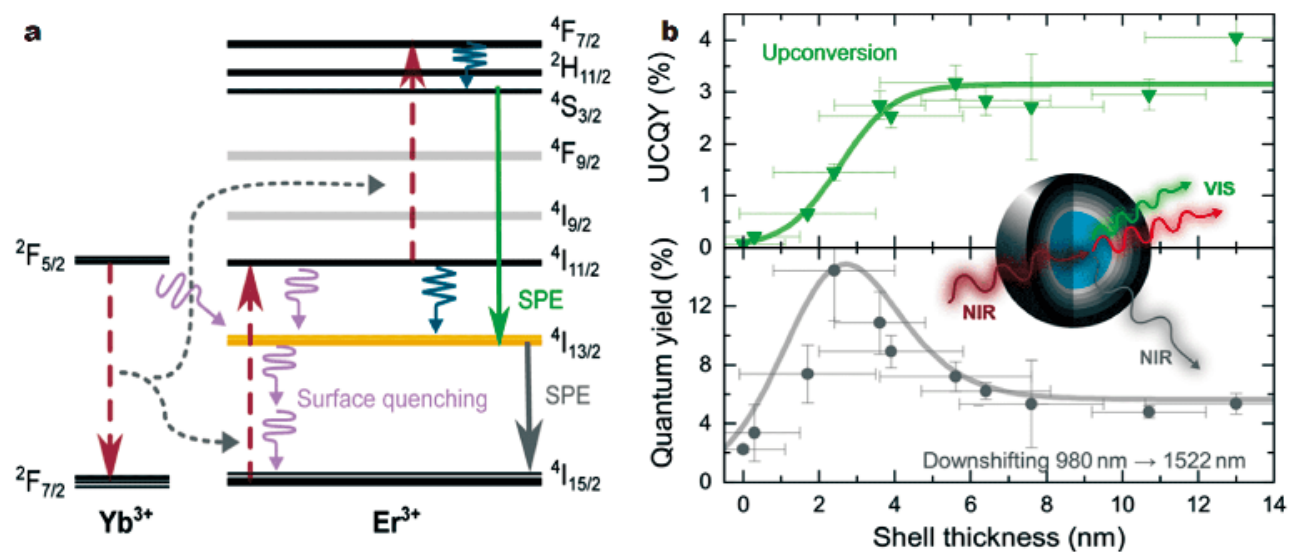

Figure 5 (a) Scheme illustration of the SQAD model in $\mathrm{NaYF}_{4}: \mathrm{Yb} / \mathrm{Er} @ \mathrm{NaYF}_{4}$ core/shell NPs. (b) Shell thickness-dependent UC QY (green) and NIRII QY (gray) of $\mathrm{Er}^{3+}$ in $\mathrm{NaYF}_{4}: \mathrm{Yb} / \mathrm{Er} @ \mathrm{NaYF}_{4}$ core/shell NPs upon excitation at $980 \mathrm{~nm}$. Adapted with permission from Ref. [66]. Copyright 2016, American Chemical Society. 
modified on the surface of $\mathrm{Ln}^{3+}$-doped NPs to improve their hydrophilicity.

\section{BIOIMAGING}

Bioimaging techniques are widely applied in clinical diagnosis and therapy. Among various bioimaging modalities, optical bioimaging attracts reviving interest due to its fast response, high sensitivity and superior resolution. However, there remains a challenge of conventional fluorescent probes for bioimaging, due to their inherent limitations like shallow tissue penetration and poor signal-to-noise ratio (SNR). In recent years, $\mathrm{Ln}^{3+}$-doped NIR-II NPs have been considered as promising luminescent nanoprobes for bioimaging. The emission wavelength, excitation wavelength and PL lifetime can be exquisitely manipulated by changing the $\mathrm{Ln}^{3+}$ dopants, hosts and structure of nanomaterials, which renders them an ideal candidate for use in diverse bioimaging applications.

The NIR-II emissions of $\mathrm{Ln}^{3+}$-doped NPs can be tuned to meet the requirements of the in vitro and in vivo bioimagings. In the past few years, several $\mathrm{Nd}^{3+}$-doped NPs such as $\mathrm{NdF}_{3} @ \mathrm{SiO}_{2}$ [95], $\mathrm{CaTiO}_{3}: \mathrm{Nd}$ [98], $\quad \mathrm{NaGdF}_{4}: \mathrm{Nd} @ \mathrm{NaGdF}_{4}$ [99], $\mathrm{LiLuF}_{4}: \mathrm{Nd} @ L i L u F_{4}$ [100] and $\mathrm{NaYF}_{4}: \mathrm{Nd} @ \mathrm{NaGdF}_{4}$ [101] were extensively investigated as probes for bioimaging. Among them, $\mathrm{NdF}_{3} @ \mathrm{SiO}_{2} \mathrm{NPs}$ exhibiting emission from ${ }^{4} \mathrm{~F}_{3 / 2} \rightarrow{ }^{4} \mathrm{I}_{11 / 2}$ of $\mathrm{Nd}^{3+}$ centered at $\sim 1,060 \mathrm{~nm}$ were first employed by Wang et al. [95] for bioimaging of living tissues in 2008. However, Villa et al. [28] pointed out that NPs emitting around $1,000 \mathrm{~nm}$ failed to completely eliminate the autofluorescence from the strong NIR fluorescence $(\sim 1,100 \mathrm{~nm})$ generated by the mouse food upon excitation at $808 \mathrm{~nm}$. To overcome this issue, they utilized the NIR-II emission from ${ }^{4} \mathrm{~F}_{3 / 2} \rightarrow{ }^{4} \mathrm{I}_{13 / 2}$ of $\mathrm{Nd}^{3+}$ centered at $1,340 \mathrm{~nm}$ from $\mathrm{SrF}_{2}: \mathrm{Nd} \mathrm{NPs}$ for deep-tissue and autofluorescence-free in vivo imaging. Moreover, Wang et al. [102] compared the penetration depth between emission at 1,060 and $1,525 \mathrm{~nm}$ in bioimaging. It was found that the emission light of $1,525 \mathrm{~nm}$ showed higher penetration depth than that of $1,060 \mathrm{~nm}$ (Fig. 6a, b). Subsequently, Diao et al. [23] also proposed that in vivo imaging based on emission beyond 1,500 $\mathrm{nm}$ afforded the high SNR and superior spatial resolution in bioimaging. The

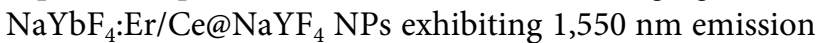
were employed for bioimaging of the blood vasculature in the hindlimb of mouse. The SNR of NIR-II bioimaging was determined to be 4.50 , which is much higher than that of NIR-I bioimaging (i.e., 1.19). Meanwhile, a spatially resolved blood-flow map in the mouse brain can be captured in a very short exposure time (20 ms) (Fig. 6c-e) [67]. Inspired by this work, $\mathrm{NaYF}_{4}: \mathrm{Gd} / \mathrm{Yb} / \mathrm{Er}$ nanorods were applied for bioimaging of tiny tumor $(4 \mathrm{~mm}$ in diameter), by virtue of the highly efficient NIR-II emission at $1,520 \mathrm{~nm}$ of $\mathrm{Er}^{3+}$ [73].

Besides the emission wavelength, the selection of excitation wavelength is also of vital importance. Nowadays, the majority of $\mathrm{Ln}^{3+}$-doped NIR-II nanoprobes were excited at $980 \mathrm{~nm}$, where $\mathrm{Yb}^{3+}$ ions were used as sensitizer. Typical examples include $\mathrm{NaYF}_{4}: \mathrm{Yb} / \mathrm{Er}$ [46], $\mathrm{NaCeF}_{4}: \mathrm{Er} / \mathrm{Yb} @ \mathrm{NaCeF}_{4}$ [57], $\mathrm{NaYF}_{4}: \mathrm{Yb} / \mathrm{Er} / \mathrm{Mn}$ [103], to name a few. In one pioneering work, Naczynski et al. [46] demonstrated the application of $\mathrm{NaYF}_{4}: \mathrm{Yb} / \mathrm{Er} \mathrm{NPs}$ for in vivo NIR-II bioimaging upon excitation at $980 \mathrm{~nm}$ (Fig. 6f-i). Later, it was found that the excitation light of $980 \mathrm{~nm}$ might not be the ideal choice for bioimaging since the strong optical absorption of water at $980 \mathrm{~nm}$ may cause undesired tissue heating effect [104]. In this regard, the excitation at $740-800 \mathrm{~nm}$ with lower water absorption in tissue was proposed. Thus, $\mathrm{Nd}^{3+}$ as a sensitizer to harvest $\sim 800 \mathrm{~nm}$ light received increasing attention [6,105]. For instance, Wang et al. [102] synthesized multi-shelled NPs based on

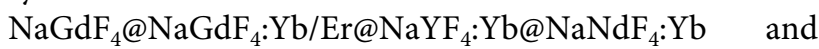
demonstrated their great potential for bioimaging in deep tissues upon excitation at $800 \mathrm{~nm}$. Likewise, Prasad et al. $[64,70]$ designed $\mathrm{NaGdF}_{4}: \mathrm{Nd@NaGdF}{ }_{4} \mathrm{NPs}$ which can be excited at $740 \mathrm{~nm}$ for bioimaging. Because tissue absorption and scattering are minimized in NIR-II spectral range, high penetration depth can be expected by tuning the excitation light from NIR-I to NIR-II region. In this regard, Liu et al. [87] presented a new type of $\mathrm{Er}^{3+}$-sensitized NPs $\left(\mathrm{NaErF}_{4}: \mathrm{Ho} @ \mathrm{NaYF}_{4}\right)$ with the excitation $(1,530 \mathrm{~nm})$ and emission $(1,180 \mathrm{~nm})$ located in NIR-II region. Nevertheless, the excitation at $1,530 \mathrm{~nm}$ locates in the strong absorption band of water, which may generate some overheating problems [106]. As such, X-rays instead of NIR light was proposed by Naczynski et al. [86] as excitation light to produce NIR-II emission of $\mathrm{Er}^{3+}$ ions from $\mathrm{NaYF}_{4}: \mathrm{Yb} / \mathrm{Er}$ NPs for lymphatic mapping (Fig. 7). The use of X-rays may overcome the problem of the limited penetration depth of NIR excitation lights.

In addition to the tuning of emission and excitation wavelength, lifetime manipulation also plays an important role in bioimaging. Taking advantage of long PL lifetime of $\mathrm{Ln}^{3+}$, del Rosal et al. [107] realized time-gated in vivo imaging by employing $\mathrm{NaGdF}_{4}$ : $\mathrm{Nd} \mathrm{NPs}$ to remove the food-related infrared autofluorescence. When the delay time was set to be $1 \mu \mathrm{s}$, short-lived background autofluorescence was no longer present while only long- 

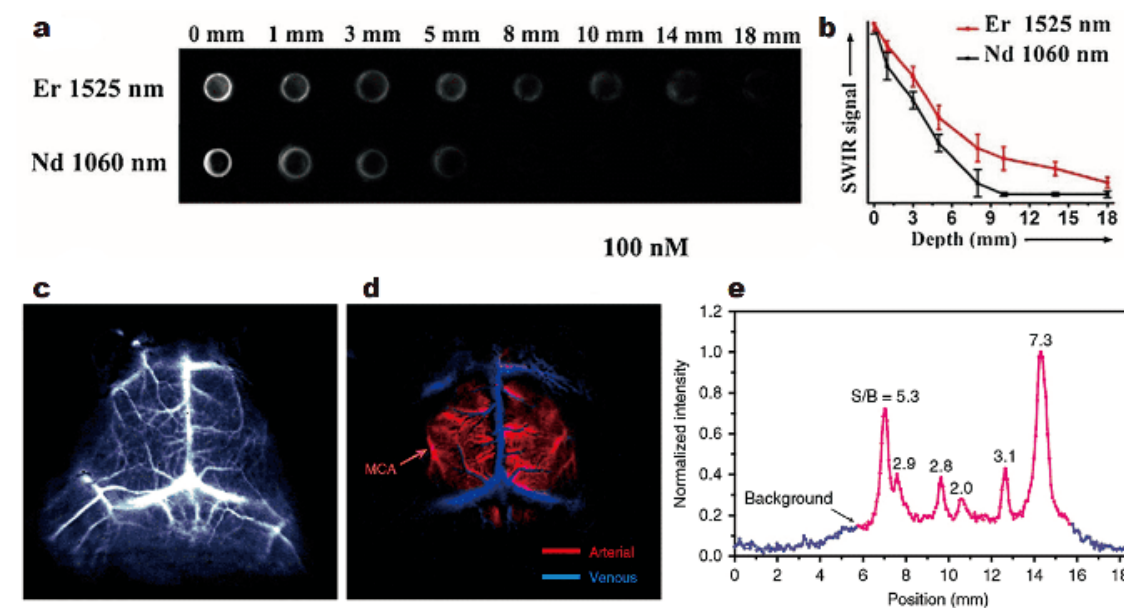

d
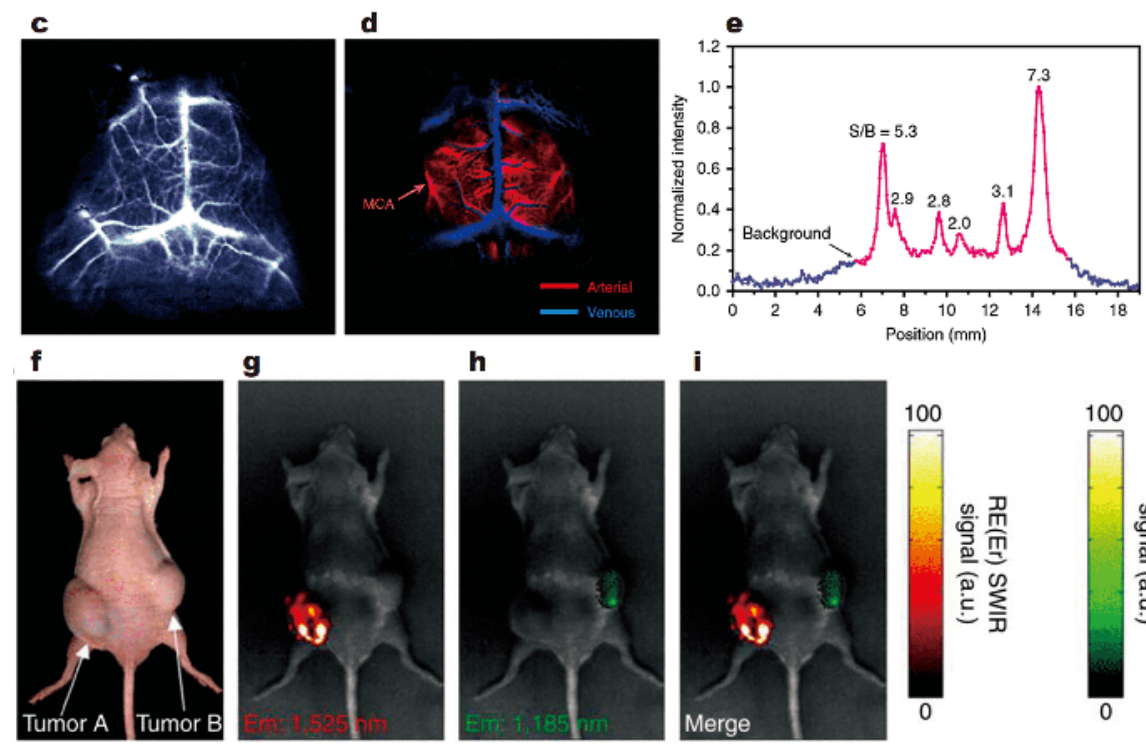

h
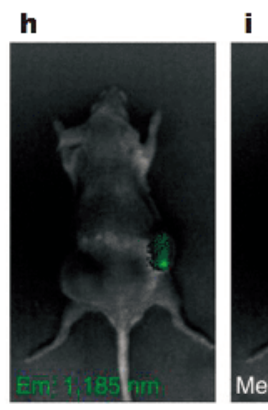

i

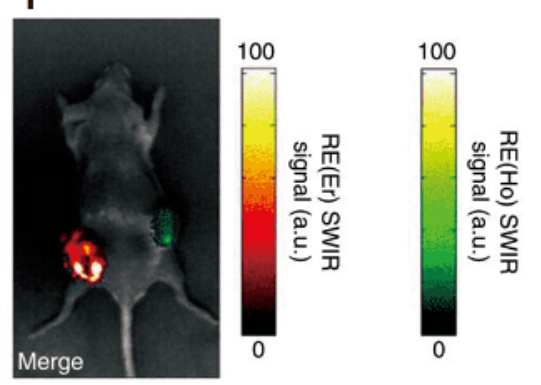

Figure 6 (a) Comparison of the penetration depth of 1,532-nm emission from $\mathrm{Er}^{3+}$ and 1,060-nm emission from $\mathrm{Nd}^{3+}$. (b) Signal intensity curve obtained from (a). Reprinted with permission from ref. [102]. Copyright 2014, Wiley-VCH Verlag GmbH \& Co. KGaA. (c) Cerebral vascular image in NIR-II region with $20 \mathrm{~ms}$ exposure time and (d) corresponding principal component analysis of overlaid image showing arterial (red) and venous (blue) vessels. (e) Signal to background (SBR) analysis of cerebrovascular image in NIR-II region. Reprinted with permission from ref. [67]. Copyright 2017, Nature Publishing Group. (f) Bright field image of the tumor-bearing nude mouse. (g-i) NIR-II in vivo imaging after injecting NaYF : $_{4} \mathrm{Yb}_{\mathrm{E}} \mathrm{Er}$ and $\mathrm{NaYF}_{4}: \mathrm{Yb} / \mathrm{Ho}$ NPs separately on left and right flank of the mouse. Reprinted with permission from ref. [46]. Copyright 2013, Nature Publishing Group.

lived emission of $\mathrm{Nd}^{3+}$ at $1,060 \mathrm{~nm}$ was detected. Owing to their tunability of PL lifetime in a wide range from $\mu$ s to $\mathrm{ms}, \mathrm{Ln}^{3+}$-doped NIR-II NPs are also an ideal candidate for time-domain multiplexing bioimaging [108]. The strategy for manipulating the PL lifetime of $\mathrm{Ln}^{3+}$-doped NIR-II NPs primarily involves the control of dopant combinations as well as the host structure [109,110]. Hitherto, only a few reports demonstrated the applicability of $\mathrm{Ln}^{3+}$-doped NIR-II NPs for in vivo multiplexing lifetime imaging. Ortgies et al. [109] achieved in vivo NIR-II lifetime-based multiplexed imaging by utilizing two types of $\mathrm{NaYF}_{4}: \mathrm{Yb}, \mathrm{Nd} @ \mathrm{CaF}_{2} \mathrm{NPs}$ with different lifetimes (Fig. 8a). The one with shorter NIR-II PL lifetime was intruded in the mouse through oral administration and the other one with longer lifetime was intruded through intravenous injection. These two types of NPs can be distinguished from the lifetime imaging by a custom-made software. Correspondingly, their different biodistribution routes after oral or intravenous adminis- tration were clearly tracked and visualized (Fig. 8b). By comparison, the biodistribution routes cannot be distinguished from intensity-based PL imaging (Fig. 8c). Furthermore, Fan et al. [110] performed in vivo multiplexed imaging by employing $\mathrm{Ln}^{3+}$-doped NIR-II NPs with engineered PL lifetimes. They carried out cancer diagnostics in vivo with three kinds of core-shell

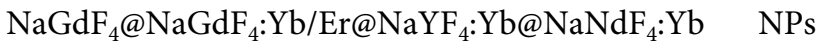
(Er-NPs) of different lifetimes conjugated with primary antibodies, which were used for targeting three typical biomarkers of MCF-7 breast cancer cells (i.e., oestrogen receptor, progesterone receptor and human epidermal growth factor receptor-2), respectively. After injecting these NPs to nude mice bearing xenografted tumors, the biomarker expressions of the three markers can be identified by lifetime imaging. Their result showed excellent correlation with conventional immunohistochemical methods, indicating that lifetime imaging is a feasible approach for accurate quantification 

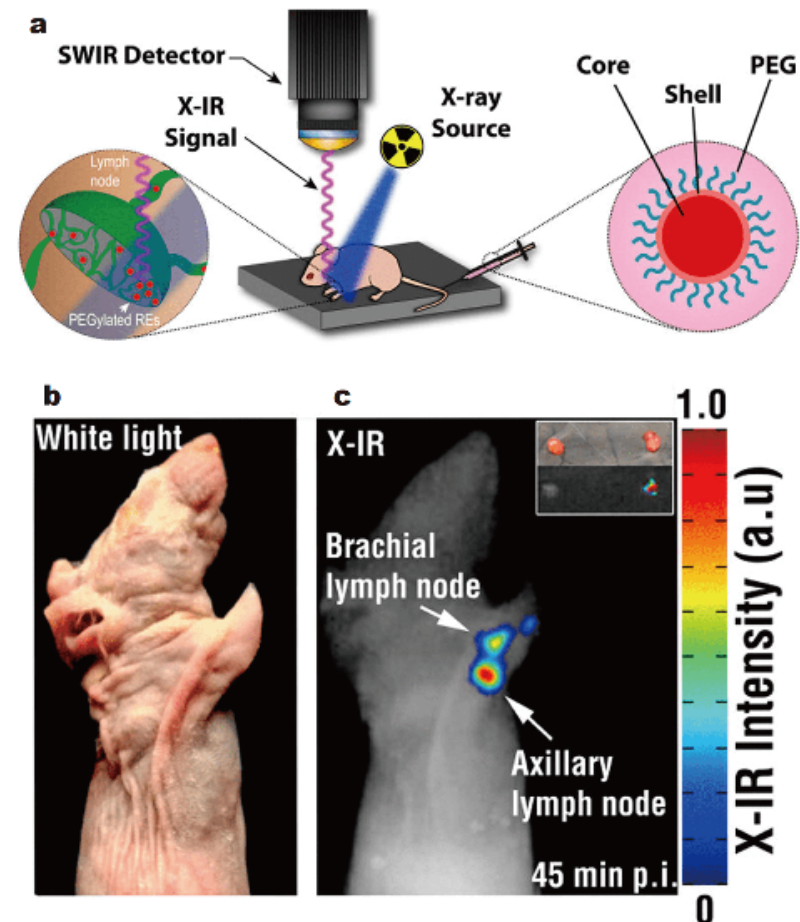

Figure 7 (a) Schematic diagram of in vivo NIR-II imaging based on PEGylated $\mathrm{NaYF}_{4}: \mathrm{Yb} /$ Er NPs upon excitation with X-ray light. (b) Bright field image of nude mouse and (c) NIR-II lymphatic mapping of the mouse injected with PEGylated $\mathrm{NaYF}_{4}: \mathrm{Yb} / \mathrm{Er}$ NPs upon excitation with X-ray light. Adapted with permission from Ref. [86]. Copyright 2015, American Chemical Society.

of disease markers.

\section{BIOASSAY}

Luminescent bioassay is a powerful technique utilizing optical probes for detecting trace amount of target analytes, which is essential for many biomedical applications like pharmaceutical preparation, disease diagnosis and therapy. Currently, a variety of $\mathrm{Ln}^{3+}$-doped NPs exhibiting visible emissions have been developed for bioassays [111-116]. However, the bioassays based on $\mathrm{Ln}^{3+}$-doped NIR-II NPs have been rarely reported.

The $\mathrm{Ln}^{3+}$-doped NIR-II NPs with high NIR-II QYs are favorable for sensitive bioassays. To meet the requirement of sensitive bioassay, Lei et al. [57] recently developed a novel NIR-II nanoprobe of $\mathrm{NaCeF}_{4}: \mathrm{Er} / \mathrm{Yb} \mathrm{NPs}$. Owing to the efficient $\mathrm{Yb}^{3+}-\mathrm{Er}^{3+}-\mathrm{Ce}^{3+}$ energy transfer, a maximum NIR-II QY of $32.8 \%$ for $\mathrm{NaCeF}_{4}: \mathrm{Er} / \mathrm{Yb}$ was achieved, which was higher than that of other $\mathrm{Er}^{3+}$-activated nanoprobes. They found that the NIR-II emission of $\mathrm{Er}^{3+}$ in $\mathrm{NaCeF}_{4}: \mathrm{Er} / \mathrm{Yb}$ NPs can be effectively inhibited by $\mathrm{H}_{2} \mathrm{O}_{2}$, due to the redox reaction between the $\mathrm{Ce}^{3+}$ ions and $\mathrm{H}_{2} \mathrm{O}_{2}$ (Fig. 9a). The limit of detection (LOD) for $\mathrm{H}_{2} \mathrm{O}_{2}$ was
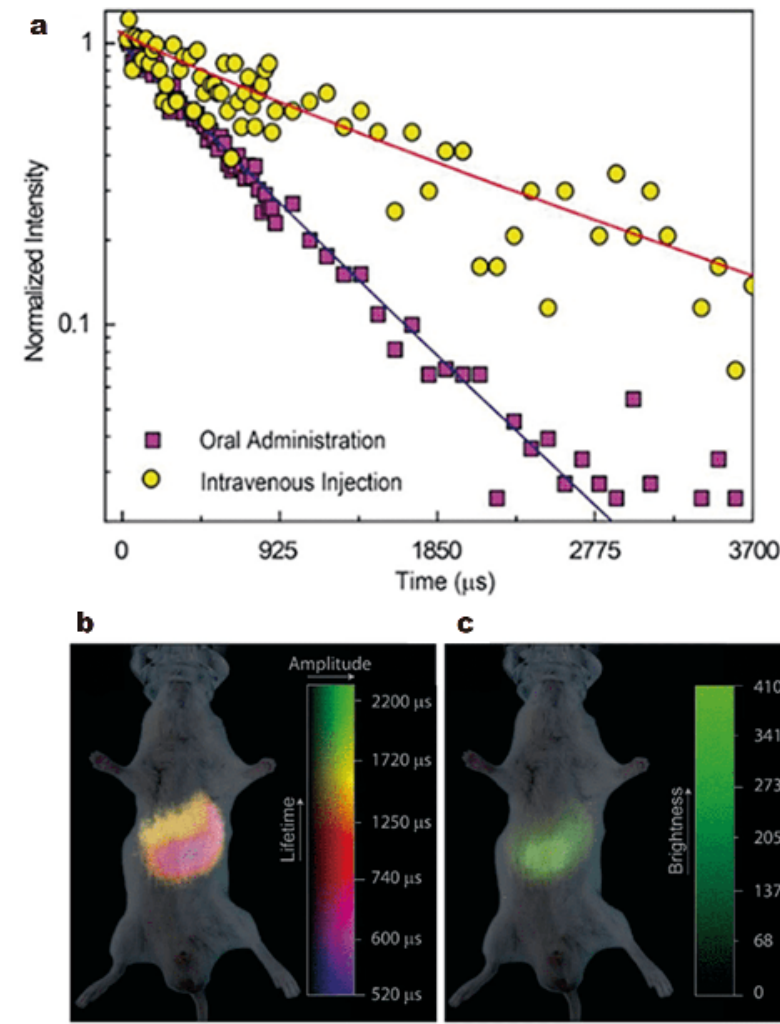

c

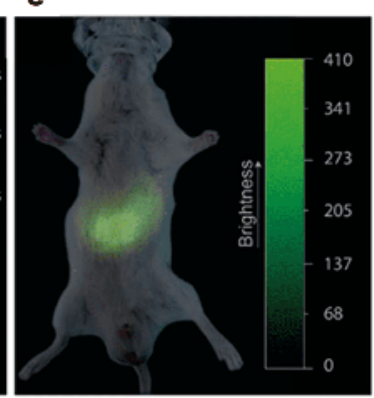

Figure 8 (a) PL decays of two types of NPs $\left(\mathrm{NaY}_{0.9-x} \mathrm{Yb}_{0.1} \mathrm{Nd}_{x} \mathrm{~F}_{4} @ \mathrm{CaF}_{2}\right.$, $x=0.2$ and 0.3 , respectively). In vivo multiplexed imaging of mouse after oral and intravenous injection of these two types of NPs based on (b) PL lifetime and (c) PL intensity. Adapted with permission from Ref. [109]. Copyright 2018, American Chemical Society.

determined to be $41.8 \mathrm{nmol} \mathrm{L}^{-1}$ by using $\mathrm{NaCeF}_{4}: \mathrm{Er} / \mathrm{Yb}$ nanoprobes (Fig. 9b, c). Based on the $\mathrm{H}_{2} \mathrm{O}_{2}$-responsive luminescence, we also demonstrated their application as homogeneous nanoprobes to detect uric acid (UA), since $\mathrm{H}_{2} \mathrm{O}_{2}$ can be produced through the UA/uricase reaction (Fig. 9d-f). Accordingly, an LOD of $25.6 \mathrm{nmol} \mathrm{L}^{-1}$ was achieved for UA. Moreover, the concentrations of UA in serum samples determined by the $\mathrm{NaCeF}_{4}: \mathrm{Er} / \mathrm{Yb} \mathrm{NPs}$ were highly consistent with those measured by commercial kit, indicative of the assay's accuracy and reliability. These results revealed the great potential of $\mathrm{Ln}^{3+}$ doped NIR-II NPs for practical in vitro detection of disease markers.

To show the superiority of $\mathrm{Ln}^{3+}$-doped NIR-II NPs for in vivo bioassays, Zhang and co-workers [87] reported another NIR-II nanoprobe of $\mathrm{NaErF}_{4}: \mathrm{Ho}_{0} \mathrm{NaYF}_{4} \mathrm{NPs}$ with both excitation $(1,530 \mathrm{~nm})$ and emission $(1,180 \mathrm{~nm})$ located in the NIR-II region. For $\mathrm{NaErF}_{4}: \mathrm{Ho}_{0} \mathrm{NaYF}_{4}$ $\mathrm{NPs}, \mathrm{Er}^{3+}$ ions acted as both sensitizer and emitter for harvesting pump photons at $1,530 \mathrm{~nm}$ and subsequently 
a
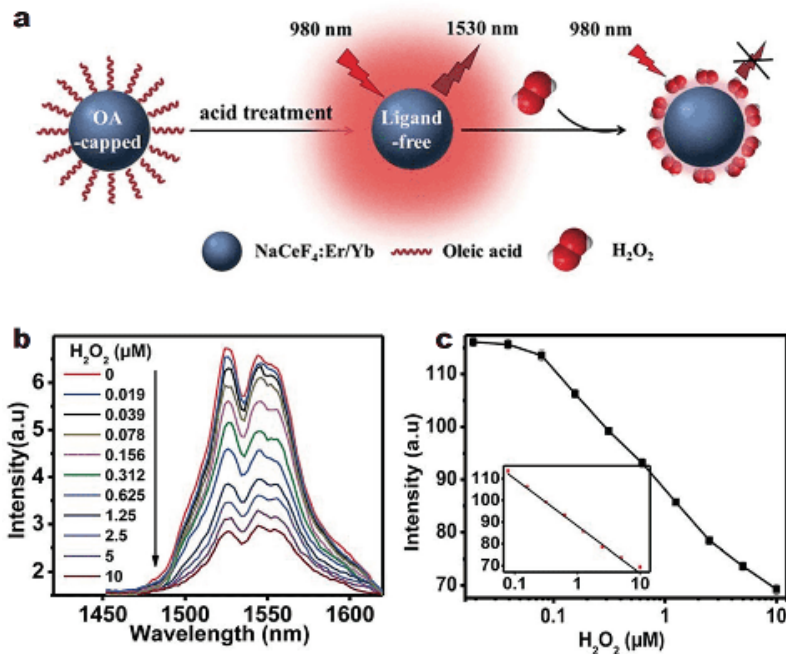

d

$\mathrm{UA}+$ Uricase $+\mathrm{H}_{2} \mathrm{O}+\mathrm{O}_{2} \rightarrow$ Allantoin $+\mathrm{H}_{2} \mathrm{O}_{2}+\mathrm{CO}_{2}$
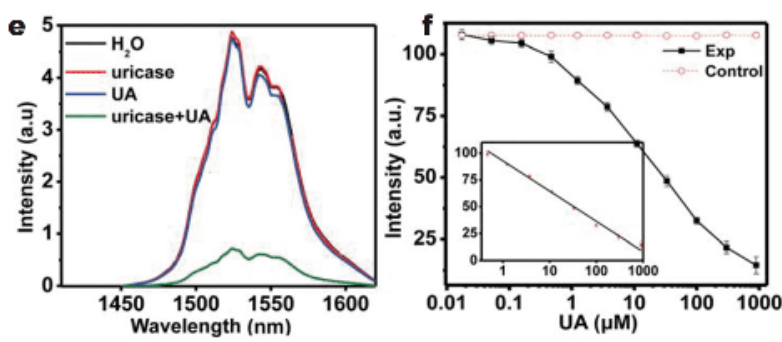

Figure 9 (a) Schematic illustration of the procedure for homogeneous assay of $\mathrm{H}_{2} \mathrm{O}_{2}$ with $\mathrm{NaCeF}_{4}$ : $\mathrm{Er} / \mathrm{Yb}$ NPs. (b) NIR-II emission intensity of ligand-free $\mathrm{NaCeF}_{4}: \mathrm{Er} / \mathrm{Yb} \mathrm{NPs}$ with different concentrations of $\mathrm{H}_{2} \mathrm{O}_{2}$, upon excitation at $980 \mathrm{~nm}$. (c) Calibration curve for homogeneous assay of $\mathrm{H}_{2} \mathrm{O}_{2}$. Inset reveals the linear region of the calibration curve $\left(0.078-10 \mu \mathrm{mol} \mathrm{L}{ }^{-1}\right)$. (d) Chemical equation for the generation of $\mathrm{H}_{2} \mathrm{O}_{2}$ via UA/uricase reaction. (e) NIR-II emission spectra of $\mathrm{NaCeF}_{4}: \mathrm{Er} / \mathrm{Yb}$ NPs after adding $\mathrm{H}_{2} \mathrm{O}$, uricase, $\mathrm{UA}$ and uricase + UA, respectively, upon excitation at $980 \mathrm{~nm}$. (f) Calibration curve of UA assay. Inset reveals the linear region of the calibration curve $\left(0.411-900 \mu \mathrm{mol} \mathrm{L}^{-1}\right)$. Adapted with permission from Ref. [57]. Copyright 2018, the Royal Society of Chemistry.

generating the UC emission at $980 \mathrm{~nm}$. Meanwhile, $\mathrm{Ho}^{3+}$ ions also served as an emitter to produce UC emission at $1,180 \mathrm{~nm}$. By virtue of the multiple emissions, the proposed NIR-II NPs can be utilized as ratiometric fluorescent $\mathrm{H}_{2} \mathrm{O}_{2}$ sensor. Specifically, $\mathrm{NaErF}_{4}$ :Ho@NaYF${ }_{4} \mathrm{NPs}$ and organic chromophore probe IR1061 with strong absorption at $800-1,100 \mathrm{~nm}$ were encapsulated in polycaprolactone. In the absence of $\mathrm{H}_{2} \mathrm{O}_{2}$, the $980 \mathrm{~nm}$ emission $\left(I_{980}\right)$ of $\mathrm{Er}^{3+}$ was suppressed due to the strong absorption of IR1061. Nevertheless, $\mathrm{H}_{2} \mathrm{O}_{2}$ may induce the destruction of IR1061, and thus weaken its absorption from 800 to $1,100 \mathrm{~nm}$ (Fig. 10a). As a result, $I_{980}$ may gradually recover with increasing of the $\mathrm{H}_{2} \mathrm{O}_{2}$ concentration. By contrast, the intensity of $1,180 \mathrm{~nm}$ emis- sion $\left(I_{1180}\right)$ of $\mathrm{Ho}^{3+}$ was not affected by $\mathrm{H}_{2} \mathrm{O}_{2}$. Therefore, the concentration of $\mathrm{H}_{2} \mathrm{O}_{2}$ can be quantified by determining the PL intensity ratio $I_{980} / I_{1180}$ (Fig. 10b). As a proof-of-concept experiment, they fabricated the microneedle patches based on the $\mathrm{NaErF}_{4}: \mathrm{Ho@NaYF}$ NPs and IR1061 encapsulated polycaprolactone, which were applied for in vivo bioassay of $\mathrm{H}_{2} \mathrm{O}_{2}$ in the inflammation site (Fig. 10c). By taking advantage of low autofluorescence of the NIR-II emission, the PL images of the microneedle array can be clearly observed under the skin tissue of mice. Upon excitation at $1,530 \mathrm{~nm}$, the PL signal of $1,180 \mathrm{~nm}$ was stable while the signal of $980 \mathrm{~nm}$ gradually increased as the evolution of inflammation with the continuous generation of $\mathrm{H}_{2} \mathrm{O}_{2}$ (Fig. 10d). According to the linear correlation between $\mathrm{H}_{2} \mathrm{O}_{2}$ concentration and $\log \left(I_{980} / I_{1180}\right)$, the concentration deviation of $\mathrm{H}_{2} \mathrm{O}_{2}$ in the inflammatory site can be monitored from 0 to $12 \mathrm{~h}$, which provides a feasible strategy for the quantitative detection of disease markers in vivo.

\section{TEMPERATURE SENSING}

Luminescent nanothermometers are widely applied in nanomedicine, physiology, medical diagnosis, and controllable hyperthermia treatment. Particularly, luminescent nanothermometers, which are suitable for contactless, non-invasive temperature measurement at sub-cellular level, have gained much attention when it comes to photothermal therapeutics. Moreover, high-resolution temperature sensing is highly desired not only at the cellular level but also for in vivo disease diagnosis. As mentioned above, the NIR-II emission can penetrate much deeper in the biological tissue than visible or NIR-I emissions. Thus, nanothermometers with temperaturedependent emission in the NIR-II region are ideal candidates for temperature sensing at the deep tissue level [117].

The energy gap between some Stark sublevels of $\mathrm{Ln}^{3+}$ ions is very small (only few tens of wavenumbers), which is strongly thermally coupled. Therefore, small temperature variations may result in remarkable changes in their emitting intensity due to the population redistribution of the thermally coupled energy levels. Such temperature dependent population of excited electrons in different energy levels of $\mathrm{Ln}^{3+}$ allows for ratiometric nanothermometry based on the intensity ratio of two emission bands.

Among all the $\mathrm{Ln}^{3+}$-doped NIR-II nanothermometers, $\mathrm{Nd}^{3+}$-based NPs (e.g., $\mathrm{YVO}_{4}: \mathrm{Nd}$ [120], $\mathrm{Gd}_{2} \mathrm{O}_{3}: \mathrm{Nd}$ [121], $\mathrm{YAlO}_{3}: \mathrm{Nd}$ [122], $\mathrm{LaF}_{3}: \mathrm{Nd} @ \mathrm{LaF}_{3}: \mathrm{Yb}$ [118],) received the greatest attention. One of the most representative ex- 

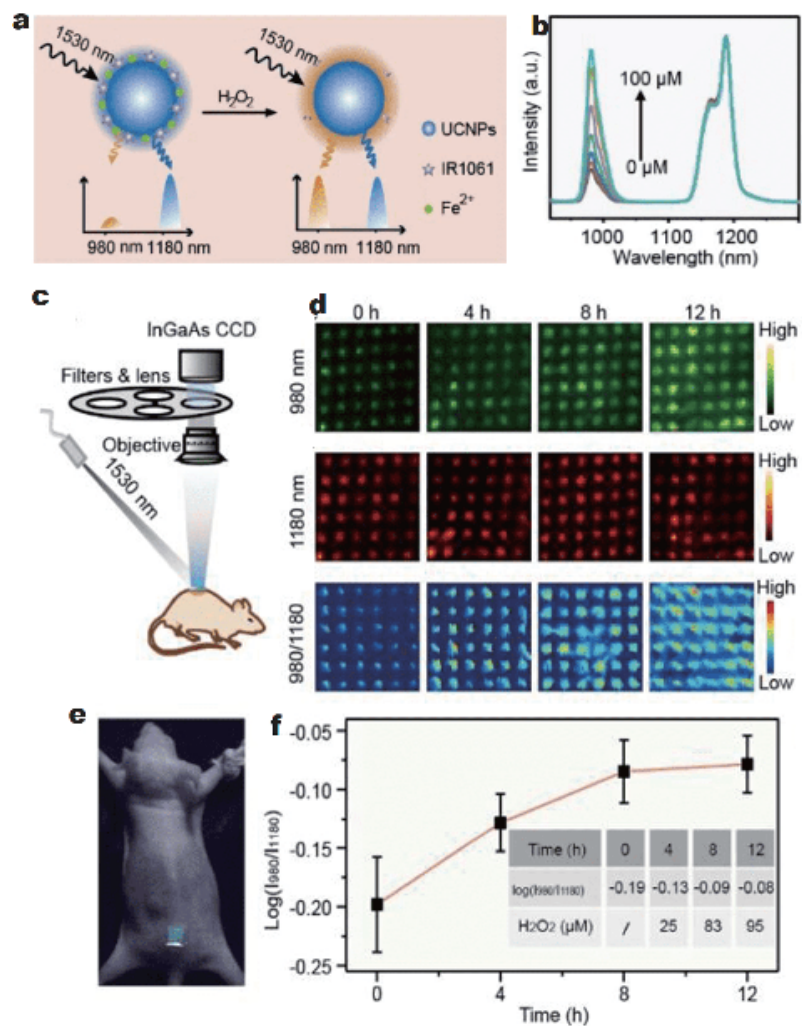

Figure 10 (a) Schematic illustration of ratiometric luminescent assay for $\mathrm{H}_{2} \mathrm{O}_{2}$. (b) UC emission spectra of $\mathrm{NaErF}_{4}: \mathrm{Ho} @ \mathrm{NaYF}_{4} \mathrm{NPs}$ and IR1061 encapsulated polycaprolactone upon addition of different concentrations of $\mathrm{H}_{2} \mathrm{O}_{2}$. (c) Schematic illustration of the experiment for in vivo bioassay of $\mathrm{H}_{2} \mathrm{O}_{2}$. (d) UC luminescence images at $980 \mathrm{~nm}$ (top), $1,180 \mathrm{~nm}$ (middle), and the ratio of 980 to $1,180 \mathrm{~nm}$ (bottom) of microneedle patches taken at different times after lipopolysaccharide induced inflammation. (e) Photograph of the mouse treated with the microneedle patch. (f) Ratiometric luminescence of microneedle patches at different times with corresponding $\mathrm{H}_{2} \mathrm{O}_{2}$ concentration. Reprinted with permission from Ref. [87]. Copyright 2018, Wiley-VCH Verlag $\mathrm{GmbH} \&$ Co. KGaA.

amples of $\mathrm{Nd}^{3+}$-based nanothermometers was reported by Kolesnikov and co-workers [120], who synthesized $\mathrm{YVO}_{4}: \mathrm{Nd}$ with NIR-II emission band from ${ }^{4} \mathrm{~F}_{3 / 2} \rightarrow{ }^{4} \mathrm{I}_{11 / 2}$ of $\mathrm{Nd}^{3+}$ for ratiometic temperature sensing. The integrated intensity ratio of 1,062 and $1,072 \mathrm{~nm}$ decreased from 25 to $55^{\circ} \mathrm{C}$ with thermal sensitivity of $\sim 0.2 \% /{ }^{\circ} \mathrm{C}$. Carlos and co-workers proposed another kind of NIR-II nanothermometer based on $\mathrm{Gd}_{2} \mathrm{O}_{3}$ : Nd NPs with temperature sensitivity of $\sim 0.23 \% /{ }^{\circ} \mathrm{C}$, which was assessed by the ratio between the integrated intensity of the transitions originated from the highest- and lowest-energy Stark sublevels from ${ }^{4} \mathrm{~F}_{3 / 2}$ of $\mathrm{Nd}^{3+}$ [121]. Although some progress of NIR II nanothermometry was gained in the past decade, the sensitivity of such nanothermometers was relatively low.
To this regard, Ximendes et al. [118] designed $\mathrm{LaF}_{3}: \mathrm{Nd} @ \mathrm{LaF}_{3}: \mathrm{Yb}$ core/shell NPs as nanothermometers upon the excitation at $790 \mathrm{~nm}$. In their work, the integrated intensity ratio of $\mathrm{Yb}^{3+}$ and $\mathrm{Nd}^{3+}$ NIR-II emissions was found to decrease with the temperature from 10 to $50^{\circ} \mathrm{C}$. A 4 -fold higher sensitivity $\left(0.44 \% /{ }^{\circ} \mathrm{C}\right)$ was achieved than that of $\mathrm{LaF}_{3}: \mathrm{Nd} / \mathrm{Yb}$ core-only NPs. Moreover, the proposed nanothermometer enabled monitoring of the real-time subcutaneous temperature (Fig. 11). After laserinduced heating, the subcutaneous temperature variation can be identified by the luminescent nanothermometry in a living animal (Fig. 11d), thus demonstrating the promise of $\mathrm{Ln}^{3+}$-doped NIR-II nanothermometer in subtissue temperature monitoring.

To further improve the sensitivity, other cations like $\mathrm{Cr}^{3+}$ and $\mathrm{Mn}^{2+}$ were also introduced into nanothermometry, due to their highly sensitive temperature dependent emission [106,123]. For example, nanothermometers based on the integrated intensity ratio of $\mathrm{Cr}^{3+}$ and $\mathrm{Nd}^{3+}$ emissions from $\mathrm{LiLaP}_{4} \mathrm{O}_{12}: \mathrm{Cr} / \mathrm{Nd} \mathrm{NPs}$ presented an outstanding sensitivity of $4.89 \% /{ }^{\circ} \mathrm{C}$, which was one order of magnitude higher than that of the vast majority of lu-

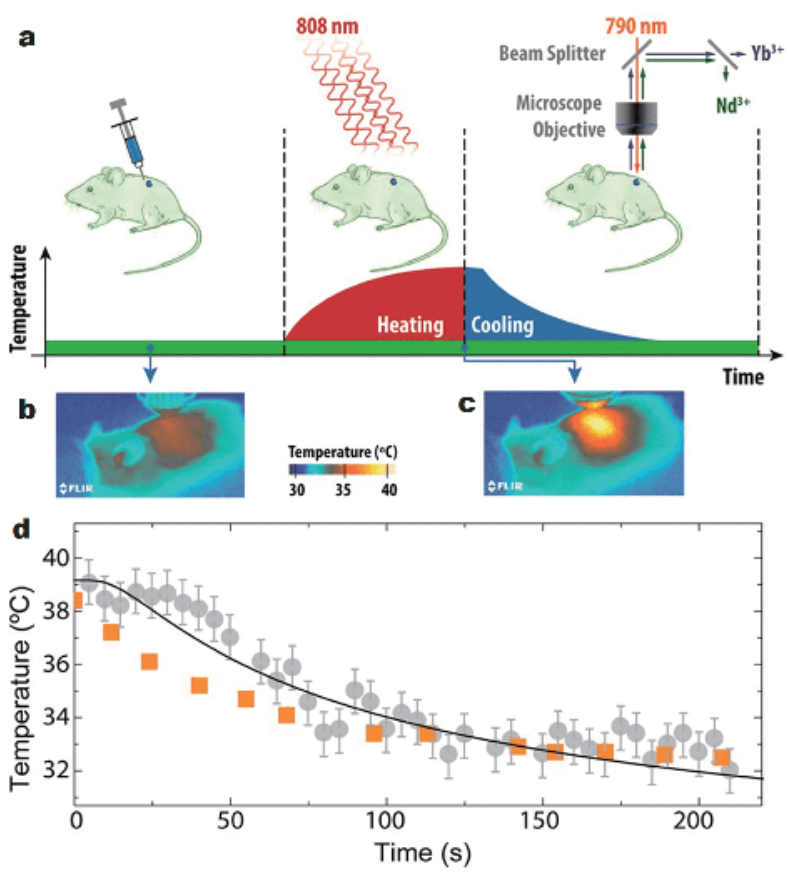

Figure 11 (a) Schematic diagram of subcutaneous temperature sensing of mouse based on $\mathrm{LaF}_{3}: \mathrm{Nd} @ \mathrm{LaF}_{3}: \mathrm{Yb}$ core/shell NPs with 808-nm laser as heating source. Thermal images of mouse (b) before and (c) after heating treatment. (d) Time evolution of the subcutaneous temperature measured by luminescent nanothermometer (gray) and skin temperature measured by IR thermal camera (orange), respectively. Adapted with permission from Ref. [118]. Copyright 2016, American Chemical Society. 
$\mathbf{a}$
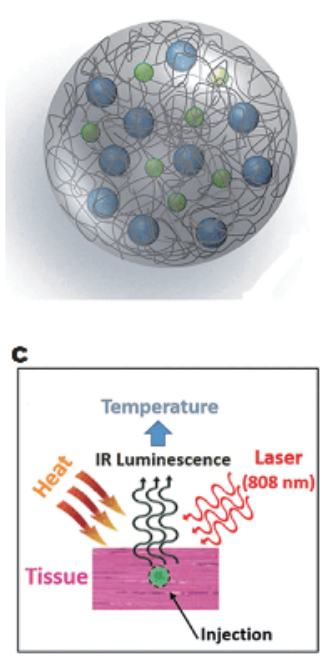
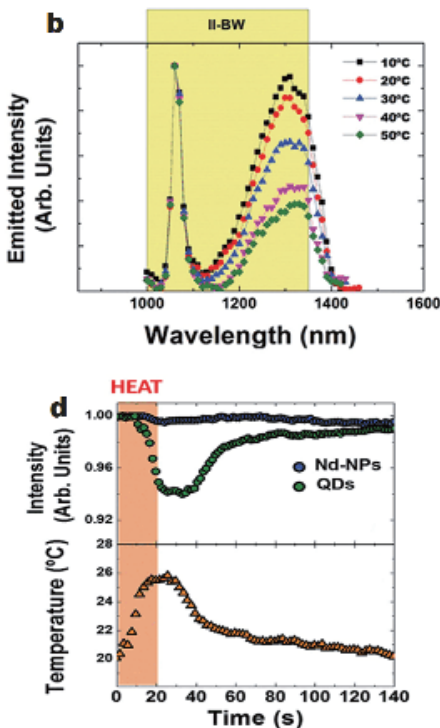

Figure 12 (a) Schematic illustration of the nanostructure consisting of $\mathrm{NaGdF}_{4}: \mathrm{Nd}^{3+}$ and $\mathrm{PbS} / \mathrm{CdS} / \mathrm{ZnS}$ QDs. (b) Temperature-dependent emission spectra of the hybrid nanocomposites upon excitation at $808 \mathrm{~nm}$. (c) Schematic diagram of in vitro temperature measurement based on the hybrid nanocomposites upon excitation at $808 \mathrm{~nm}$. (d) Evolution of the emission intensity of $\mathrm{NaGdF}_{4}: \mathrm{Nd} \mathrm{NPs}$ and $\mathrm{PbS} / \mathrm{CdS} / \mathrm{ZnS}$ QDs in the hybrid nanocomposites injected in chicken breast tissue (top) and temperature evolution of tissue (bottom) determined by the hybrid nanocomposites during a heating/cooling cycle. Reprinted with permission from ref. [119]. Copyright 2015, Wiley-VCH Verlag GmbH \& Co. KGaA.

minescent thermometers. However, the emission of $\mathrm{Cr}^{3+}$ ions $(820-840 \mathrm{~nm})$ located in NIR-I region, which to some extent restricted their applications for temperature sensing in vivo.

Very recently, several interesting studies were reported by employing the hybrid structured nanothermometers for sensitive temperature sensing [119,124-127]. Rodríguez et al. [119] designed a hybrid nanothermometer for subtissue temperature sensing (Fig. 12). This hybrid nanothermometer was prepared following a double-emulsion encapsulation procedure by $\mathrm{PbS} / \mathrm{CdS} / \mathrm{ZnS}$ QDs as temperature-sensitve response unit and temperature-insensitive $\mathrm{NaGdF}_{4}: \mathrm{Nd}$ as internal standard unit for the deep tissue ratiometric thermal sensing (Fig. 12b). The thermal sensitivity of the developed hybrid nanostructures was determined to be $2.5 \% /{ }^{\circ} \mathrm{C}$, which was one order of magnitude higher than that of the available NIRI nanothermometers $[128,129]$. Subsequently, Xu et al. [124] further improved the thermal sensitivity. Triplettriplet annihilation (TTA) dyad was modified on the surface of $\mathrm{NaYF}_{4}: \mathrm{Nd}$ to design an organic/inorganic hybrid ratiometric thermometer (Fig. 13). The proposed

organic/inorganic hybrid nanothermometer was applied to monitor the specific temperature variations and map the temperature distributions in the inflammatory mode, which exhibited high thermal sensitivity $\left(\sim 7.1 \% /{ }^{\circ} \mathrm{C}\right)$ and resolution $\left(\sim 0.1^{\circ} \mathrm{C}\right)$. Nevertheless, the emission of TTA lay in the visible region, and double beam excitations combined with two detectors (PMT and InGaAs detectors) were required (Fig. 13a). In addition, different attenuation through tissue of the emission signal of $540 \mathrm{~nm}$ from TTA and 1,060 nm from $\mathrm{NaYF}_{4}$ : Nd might deteriorate the measurement accuracy in vivo.

\section{CONCLUSIONS AND PROSPECTS}

$\mathrm{Ln}^{3+}$-doped NIR-II NPs, emerging as a novel class of luminescent probes and a promising alternative to conventional NIR-II probes, have gained substantial attention in recent years. Their optical performance can be modulated and PL efficiency can be improved via host selection, intentional cation incorporation, or surface modification with inorganic/organic layers. As a result, a series of highly efficient $\mathrm{Ln}^{3+}$-doped NIR-II probes have been developed. By taking advantage of the distinct optical features of $\mathrm{Ln}^{3+}$ ions along with the large penetration depth and low autofluorescence of NIR-II emission in biological media, these $\mathrm{Ln}^{3+}$-doped NIR-II NPs have been exploited for various applications in bioimaging, bioassay and temperature sensing.

Despite these encouraging achievements, it remains challenging for the practical bioapplications of these $\mathrm{Ln}^{3+}$. doped NIR-II nanoprobes. One of the key bottlenecks that prevent the utilization of $\mathrm{Ln}^{3+}$-doped NIR-II nanoprobes is their poor QYs caused by low absorption cross-section of $\mathrm{Ln}^{3+}$, since low PL QY may greatly reduce the SNR of bioimaging and the sensitivity of bioassay. Most of the host materials are relatively inert in the luminescence process of $\mathrm{Ln}^{3+}$ emitters, leaving large room for improvement. Therefore, future efforts should be made to explore more innovative host materials and sensitization strategies aiming to improve the NIR-II QY of $\mathrm{Ln}^{3+}$-doped NPs. Additionally, the ultimate goal in this field is to develop commercial assay kits based on $\mathrm{Ln}^{3+}$ doped NIR-II nanoprobes for in vivo disease theranostics. Although several kinds of $\mathrm{Ln}^{3+}$-doped NPs have been applied as nanoprobes for in vivo bioimaging, currently it still remains unexplored for precise bioassay in vivo. It is highly desired to design and develop novel heterogeneous/homogeneous assay techniques based on $\mathrm{Ln}^{3+}$ doped NIR-II nanoprobes for rapid, sensitive and specific bioassay of target analytes in vivo. Moreover, the narrow emission bands and tunable PL lifetimes of $\mathrm{Ln}^{3+}$-doped 
a

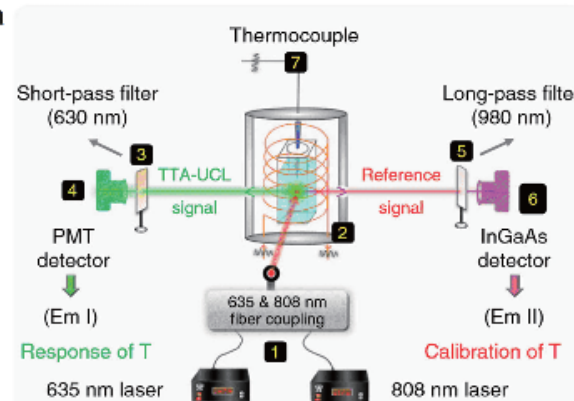

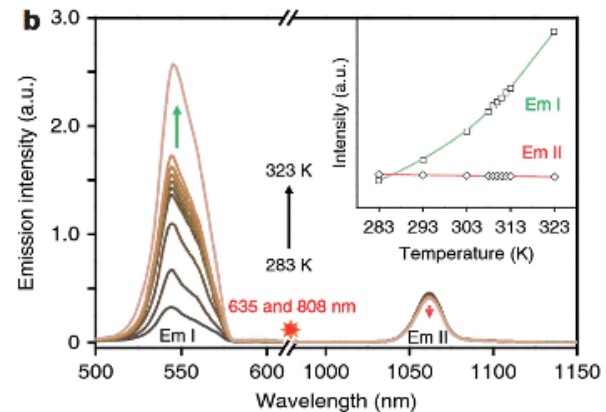
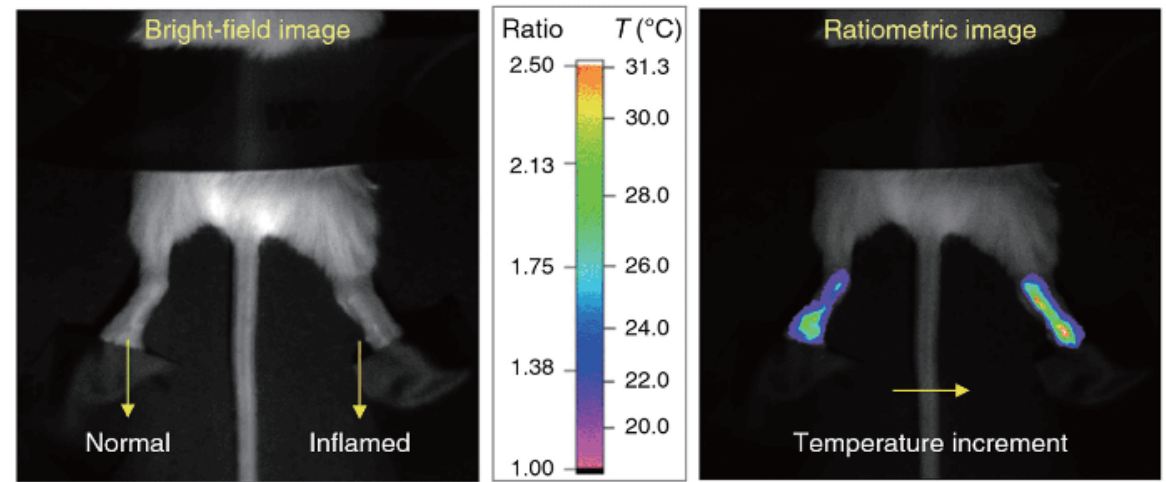

Figure 13 (a) Schematic representation of experimental device for temperature sensing based on TTA-modified NaYF $\mathrm{Nd}_{4} \mathrm{NPs}_{\text {via }}$ double beam excitations (635 and $808 \mathrm{~nm}$ ) and two detectors (PMT and InGaAs detectors). (b) Temperature-dependent emission spectra of TTA-modified $\mathrm{NaYF}_{4}: \mathrm{Nd}$ NPs from 283 to $323 \mathrm{~K}$. Inset shows the temperature dependence of the integrated emission intensities of TTA and NIR-II emission from $\mathrm{Nd}^{3+}$. (c) Bright field image (left) and the ratiometric image based on TTA-modified NaYF $\mathrm{Nd}_{4} \mathrm{NPs}_{\text {in }}$ an inflammatory mode (right) showing temperature distributions in the two legs of a mouse. Adapted with permission from Ref. [124]. Copyright 2018, Nature Publishing Group.

NPs provide unique opportunities for simultaneous multiplexed assay of different disease markers in deep tissue. Last but not the least, the prevailing in vivo imaging systems are equipped with a silicon-based chargecoupled device or complementary metal oxide semiconductor camera, which is unusable for NIR-II imaging studies. To demonstrate the potential bioapplications of $\mathrm{Ln}^{3+}$-doped NIR-II NPs, several research groups proposed different custom-built systems. As such, it is difficult to compare and evaluate the results from worldwide laboratories. There is a growing demand for the development of new-generation, but commercial cost-effective systems with highly NIR-sensitive detectors, which may significantly promote the clinical applications of NIR-II nanoprobes for sensitive bioimaging and bioassays in disease diagnosis.

Received 31 January 2019; accepted 13 March 2019; published online 17 April 2019

1 Ferrari M. Cancer nanotechnology: opportunities and challenges. Nat Rev Cancer, 2005, 5: 161-171

2 Sivaraman D, Biswas P, Cella LN, et al. Detecting RNA viruses in living mammalian cells by fluorescence microscopy. Trends Biotech, 2011, 29: 307-313

3 Cai W. Applications of gold nanoparticles in cancer nanotechnology. Nanotechnol Sci Appl, 2008, Volume 1: 17-32

4 Wang L, Dong H, Li Y, et al. Luminescence-driven reversible handedness inversion of self-organized helical superstructures enabled by a novel near-infrared light nanotransducer. Adv Mater, 2015, 27: 2065-2069

5 Zhou JC, Yang ZL, Dong W, et al. Bioimaging and toxicity assessments of near-infrared upconversion luminescent $\mathrm{NaYF}_{4}: \mathrm{Yb}$, Tm nanocrystals. Biomaterials, 2011, 32: 9059-9067

6 Hemmer E, Acosta-Mora P, Méndez-Ramos J, et al. Optical nanoprobes for biomedical applications: shining a light on upconverting and near-infrared emitting nanoparticles for imaging, thermal sensing, and photodynamic therapy. J Mater Chem B, 2017, 5: 4365-4392

7 Wei J, Zheng W, Shang X, et al. $\mathrm{Mn}^{2+}$-activated calcium fluoride nanoprobes for time-resolved photoluminescence biosensing. Sci China Mater, 2019, 62: 130-137

8 Jiang $\mathrm{X}$, Cao C, Feng W, et al. $\mathrm{Nd}^{3+}$-doped $\mathrm{LiYF}_{4}$ nanocrystals for bio-imaging in the second near-infrared window. J Mater Chem B, 2016, 4: 87-95

9 Zhou X, Cheng J, Li L, et al. A europium(III) metal-organic framework as ratiometric turn-on luminescent sensor for $\mathrm{Al}^{3+}$ ions. Sci China Mater, 2018, 61: 752-757

10 Wang D, Wang R, Liu L, et al. Down-shifting luminescence of 
water soluble $\mathrm{NaYF}_{4}: \mathrm{Eu}^{3+} @ \mathrm{Ag}$ core-shell nanocrystals for fluorescence turn-on detection of glucose. Sci China Mater, 2017, 60: 68-74

11 Liu TM, Conde J, Lipiński T, et al. Revisiting the classification of NIR-absorbing/emitting nanomaterials for in vivo bioapplications. NPG Asia Mater, 2016, 8: e295

12 Frangioni J. In vivo near-infrared fluorescence imaging. Curr Opin Chem Biol, 2003, 7: 626-634

$13 \mathrm{Xu}$ CT, Svensson N, Axelsson J, et al. Autofluorescence insensitive imaging using upconverting nanocrystals in scattering media. Appl Phys Lett, 2008, 93: 171103

14 Bashkatov AN, Genina EA, Kochubey VI, et al. Optical properties of human skin, subcutaneous and mucous tissues in the wavelength range from 400 to $2000 \mathrm{~nm}$. J Phys D-Appl Phys, 2005, 38: 2543-2555

15 Diao S, Hong G, Antaris AL, et al. Biological imaging without autofluorescence in the second near-infrared region. Nano Res, 2015, 8: 3027-3034

16 Bashkatov AN, Genina EA, Tuchin VV. Optical properties of skin, subcutaneous, and muscle tissues: a review. J Innov Opt Health Sci, 2011, 04: 9-38

17 Zhang H, Salo D, Kim DM, et al. Penetration depth of photons in biological tissues from hyperspectral imaging in shortwave infrared in transmission and reflection geometries. J Biomed Opt, 2016, 21: 126006

18 Quek CH, Leong KW. Near-infrared fluorescent nanoprobes for in vivo optical imaging. Nanomaterials, 2012, 2: 92-112

19 Hong G, Lee JC, Robinson JT, et al. Multifunctional in vivo vascular imaging using near-infrared II fluorescence. Nat Med, 2012, 18: 1841-1846

20 Hong G, Diao S, Chang J, et al. Through-skull fluorescence imaging of the brain in a new near-infrared window. Nat Photonics, 2014, 8: 723-730

21 Bruns OT, Bischof TS, Harris DK, et al. Next-generation in vivo optical imaging with short-wave infrared quantum dots. Nat Biomed Eng, 2017, 1: 0056

22 Sevick-Muraca EM. Translation of near-infrared fluorescence imaging technologies: emerging clinical applications. Annu Rev Med, 2012, 63: 217-231

23 Diao S, Blackburn JL, Hong G, et al. Fluorescence imaging in vivo at wavelengths beyond $1500 \mathrm{~nm}$. Angew Chem Int Ed, 2015, 54: 14758-14762

24 Vahrmeijer AL, Hutteman M, van der Vorst JR, et al. Imageguided cancer surgery using near-infrared fluorescence. Nat Rev Clin Oncol, 2013, 10: 507-518

25 Bhaumik S, DePuy J, Klimash J. Strategies to minimize background autofluorescence in live mice during noninvasive fluorescence optical imaging. Lab Anim, 2007, 36: 40-43

26 Inoue $\mathrm{Y}$, Izawa $\mathrm{K}$, Kiryu S, et al. Diet and abdominal autofluorescence detected by in vivo fluorescence imaging of living mice. Mol Imag, 2008, 7: 7290.2008.0003

27 Troy T, Jekic-McMullen D, Sambucetti L, et al. Quantitative comparison of the sensitivity of detection of fluorescent and bioluminescent reporters in animal models. Mol Imag, 2004, 3: 923

28 Villa I, Vedda A, Cantarelli IX, et al. $1.3 \mu \mathrm{m}$ emitting $\mathrm{SrF}_{2}: \mathrm{Nd}^{3+}$ nanoparticles for high contrast in vivo imaging in the second biological window. Nano Res, 2014, 8: 649-665

29 Li C, Wang Q. Challenges and opportunities for intravital nearinfrared fluorescence imaging technology in the second trans- parency window. ACS Nano, 2018, 12: 9654-9659

30 Fan Y, Zhang F. A new generation of NIR-II probes: lanthanidebased nanocrystals for bioimaging and biosensing. Adv Opt Mater, 2019, 1: 1801417

$31 \mathrm{Xu} \mathrm{J}$, Gulzar A, Yang P, et al. Recent advances in near-infrared emitting lanthanide-doped nanoconstructs: Mechanism, design and application for bioimaging. Coord Chem Rev, 2019, 381: 104-134

32 Yi H, Ghosh D, Ham MH, et al. M13 phage-functionalized singlewalled carbon nanotubes as nanoprobes for second near-infrared window fluorescence imaging of targeted tumors. Nano Lett, 2012, 12: 1176-1183

33 Welsher K, Sherlock SP, Dai H. Deep-tissue anatomical imaging of mice using carbon nanotube fluorophores in the second nearinfrared window. Proc Natl Acad Sci USA, 2011, 108: 8943-8948

34 O'Connell MJ, Bachilo SM, Huffman CB, et al. Band gap fluorescence from individual single-walled carbon nanotubes. Science, 2002, 297: 593-596

35 Kodach VM, Kalkman J, Faber DJ, et al. Quantitative comparison of the OCT imaging depth at $1300 \mathrm{~nm}$ and $1600 \mathrm{~nm}$. Biomed Opt Express, 2010, 1: 176

36 Choi JH, Nguyen FT, Barone PW, et al. Multimodal biomedical imaging with asymmetric single-walled carbon nanotube/iron oxide nanoparticle complexes. Nano Lett, 2007, 7: 861-867

37 Martinić I, Eliseeva SV, Petoud S. Near-infrared emitting probes for biological imaging: Organic fluorophores, quantum dots, fluorescent proteins, lanthanide(III) complexes and nanomaterials. J Lumin, 2017, 189: 19-43

38 Carr JA, Franke D, Caram JR, et al. Shortwave infrared fluorescence imaging with the clinically approved near-infrared dye indocyanine green. Proc Natl Acad Sci USA, 2018, 115: 44654470

39 Li Y, Li X, Xue Z, et al. Second near-infrared emissive lanthanide complex for fast renal-clearable in vivo optical bioimaging and tiny tumor detection. Biomaterials, 2018, 169: 35-44

40 Chen $\mathrm{G}$, Tian $\mathrm{F}$, $\mathrm{Li} \mathrm{C}$, et al. In vivo real-time visualization of mesenchymal stem cells tropism for cutaneous regeneration using NIR-II fluorescence imaging. Biomaterials, 2015, 53: 265-273

41 Hong G, Robinson JT, Zhang Y, et al. In vivo fluorescence imaging with $\mathrm{Ag}_{2} \mathrm{~S}$ quantum dots in the second near-infrared region. Angew Chem Int Ed, 2012, 51: 9818-9821

42 Semonin OE, Johnson JC, Luther JM, et al. Absolute photoluminescence quantum yields of IR-26 dye, $\mathrm{PbS}$, and $\mathrm{PbSe}$ quantum dots. J Phys Chem Lett, 2010, 1: 2445-2450

43 Hong G, Zou Y, Antaris AL, et al. Ultrafast fluorescence imaging in vivo with conjugated polymer fluorophores in the second nearinfrared window. Nat Commun, 2014, 5: 4206

44 Tsuboi S, Yamada S, Nakane Y, et al. Critical review-watersoluble near-infrared fluorophores emitting over $1000 \mathrm{~nm}$ and their application to in vivo imaging in the second optical window (1000-1400 nm). ECS J Solid State Sci Technol, 2018, 7: R3093R3101

45 Naczynski DJ, Tan MC, Riman RE, et al. Rare earth nanoprobes for functional biomolecular imaging and theranostics. J Mater Chem B, 2014, 2: 2958-2973

46 Naczynski DJ, Tan MC, Zevon M, et al. Rare-earth-doped biological composites as in vivo shortwave infrared reporters. Nat Commun, 2013, 4: 2199

47 Huang $\mathrm{P}, \mathrm{Tu} \mathrm{D}$, Zheng $\mathrm{W}$, et al. Inorganic lanthanide nanoprobes for background-free luminescent bioassays. Sci China Mater, 
2015, 58: 156-177

48 Wang J, Liu G, Engelhard MH, et al. Sensitive immunoassay of a biomarker tumor necrosis factor- $\alpha$ based on poly(guanine)functionalized silica nanoparticle label. Anal Chem, 2006, 78: 6974-6979

49 Kamaly N, Xiao Z, Valencia PM, et al. Targeted polymeric therapeutic nanoparticles: design, development and clinical translation. Chem Soc Rev, 2012, 41: 2971

50 Zheng W, Huang P, Tu D, et al. Lanthanide-doped upconversion nano-bioprobes: electronic structures, optical properties, and biodetection. Chem Soc Rev, 2015, 44: 1379-1415

51 Ding F, Zhan Y, Lu X, et al. Recent advances in near-infrared II fluorophores for multifunctional biomedical imaging. Chem Sci, 2018, 9: 4370-4380

52 Gai S, Li C, Yang P, et al. Recent progress in rare earth micro/ nanocrystals: soft chemical synthesis, luminescent properties, and biomedical applications. Chem Rev, 2014, 114: 2343-2389

53 Yang D, Ma P, Hou Z, et al. Current advances in lanthanide ion $\left(\mathrm{Ln}^{3+}\right)$-based upconversion nanomaterials for drug delivery. Chem Soc Rev, 2015, 44: 1416-1448

54 Dai $\mathrm{Y}, \mathrm{Xiao} \mathrm{H}$, Liu J, et al. In vivo multimodality imaging and cancer therapy by near-infrared light-triggered trans-platinum pro-drug-conjugated upconverison nanoparticles. J Am Chem Soc, 2013, 135: 18920-18929

55 You W, Tu D, Zheng W, et al. Large-scale synthesis of uniform lanthanide-doped $\mathrm{NaREF}_{4}$ upconversion/downshifting nanoprobes for bioapplications. Nanoscale, 2018, 10: 11477-11484

56 Zhang X, Zhao Z, Zhang X, et al. Magnetic and optical properties of $\mathrm{NaGdF}_{4}: \mathrm{Nd}^{3+}, \mathrm{Yb}^{3+}, \mathrm{Tm}^{3+}$ nanocrystals with upconversion/ downconversion luminescence from visible to the near-infrared second window. Nano Res, 2014, 8: 636-648

57 Lei $\mathrm{X}, \mathrm{Li} \mathrm{R}, \mathrm{Tu} \mathrm{D}$, et al. Intense near-infrared-II luminescence from $\mathrm{NaCeF}_{4}: \mathrm{Er} / \mathrm{Yb}$ nanoprobes for in vitro bioassay and in vivo bioimaging. Chem Sci, 2018, 9: 4682-4688

58 He X, Ma N. An overview of recent advances in quantum dots for biomedical applications. Colloids Surfs B-Biointerfaces, 2014, 124: $118-131$

59 Xu S, Cui J, Wang L. Recent developments of low-toxicity NIR II quantum dots for sensing and bioimaging. TrAC Trends Anal Chem, 2016, 80: 149-155

60 Zhao J, Zhong D, Zhou S. NIR-I-to-NIR-II fluorescent nanomaterials for biomedical imaging and cancer therapy. J Mater Chem B, 2018, 6: 349-365

61 Sharma P, Kumar Mehra N, Jain K, et al. Biomedical applications of carbon nanotubes: a critical review. Curr Drug Deliv, 2016, 13: 796-817

62 Wang $\mathrm{X}, \mathrm{Hu} \mathrm{H}$, Zhang $\mathrm{H}$, et al. Single ultrasmall $\mathrm{Mn}^{2+}$-doped $\mathrm{NaNdF}_{4}$ nanocrystals as multimodal nanoprobes for magnetic resonance and second near-infrared fluorescence imaging. Nano Res, 2017, 11: 1069-1081

$63 \mathrm{Yu} \mathrm{Z}$, Shi J, Li J, et al. Luminescence enhancement of $\mathrm{CaF}_{2}: \mathrm{Nd}^{3+}$ nanoparticles in the second near-infrared window for in vivo imaging through $\mathrm{Y}^{3+}$ doping. J Mater Chem B, 2018, 6: 1238-1243

64 Chen G, Ohulchanskyy TY, Liu S, et al. Core/shell $\mathrm{NaGdF}_{4}: \mathrm{Nd}^{3+}$ / $\mathrm{NaGdF}_{4}$ nanocrystals with efficient near-infrared to near-infrared downconversion photoluminescence for bioimaging applications. ACS Nano, 2012, 6: 2969-2977

65 Thimsen E, Sadtler B, Berezin MY. Shortwave-infrared (SWIR) emitters for biological imaging: a review of challenges and opportunities. Nanophotonics, 2017, 6: 1043-1054
66 Fischer S, Bronstein ND, Swabeck JK, et al. Precise tuning of surface quenching for luminescence enhancement in core-shell lanthanide-doped nanocrystals. Nano Lett, 2016, 16: 7241-7247

67 Zhong Y, Ma Z, Zhu S, et al. Boosting the down-shifting luminescence of rare-earth nanocrystals for biological imaging beyond 1500 nm. Nat Commun, 2017, 8: 737

68 Tan M, Del Rosal B, Zhang Y, et al. Rare-earth-doped fluoride nanoparticles with engineered long luminescence lifetime for time-gated in vivo optical imaging in the second biological window. Nanoscale, 2018, 10: 17771-17780

69 Cao C, Xue M, Zhu X, et al. Energy transfer highway in $\mathrm{Nd}^{3+}$ sensitized nanoparticles for efficient near-infrared bioimaging. ACS Appl Mater Interfaces, 2017, 9: 18540-18548

70 Shao W, Chen G, Kuzmin A, et al. Tunable narrow band emissions from dye-sensitized core/shell/shell nanocrystals in the second near-infrared biological window. J Am Chem Soc, 2016, 138: 16192-16195

71 Rocha U, Jacinto da Silva C, Ferreira Silva W, et al. Subtissue thermal sensing based on neodymium-doped $\mathrm{LaF}_{3}$ nanoparticles. ACS Nano, 2013, 7: 1188-1199

72 Wang D, Wang D, Kuzmin A, et al. ICG-sensitized $\mathrm{NaYF}_{4}: \mathrm{Er}$ nanostructure for theranostics. Adv Opt Mater, 2018, 6: 1701142

73 Xue Z, Zeng S, Hao J. Non-invasive through-skull brain vascular imaging and small tumor diagnosis based on NIR-II emissive lanthanide nanoprobes beyond $1500 \mathrm{~nm}$. Biomaterials, 2018, 171: 153-163

74 Liu Y, Luo W, Zhu H, et al. Optical spectroscopy of lanthanides doped in wide band-gap semiconductor nanocrystals. J Lumin, 2011, 131: 415-422

75 Milstein TJ, Kroupa DM, Gamelin DR. Picosecond quantum cutting generates photoluminescence quantum yields over $100 \%$ in ytterbium-doped $\mathrm{CsPbCl}_{3}$ nanocrystals. Nano Lett, 2018, 18: 3792-3799

76 Xiao Q, Zhu H, Tu D, et al. Near-infrared-to-near-infrared downshifting and near-infrared-to-visible upconverting luminescence of $\mathrm{Er}^{3+}$-doped $\mathrm{In}_{2} \mathrm{O}_{3}$ nanocrystals. J Phys Chem C, 2013, 117: 10834-10841

77 Zhou D, Liu D, Pan G, et al. Cerium and ytterbium codoped halide perovskite quantum dots: a novel and efficient downconverter for improving the performance of silicon solar cells. Adv Mater, 2017, 29: 1704149

78 Kong J, Zhu H, Li R, et al. Carrier-mediated $155 \mu \mathrm{m}$ photoluminescence from single $\mathrm{Er}^{3+}$ center in $\mathrm{SnO}_{2}$ nanocrystals. Opt Lett, 2009, 34: 1873-1875

79 Swabeck JK, Fischer S, Bronstein ND, et al. Broadband sensitization of lanthanide emission with indium phosphide quantum dots for visible to near-infrared downshifting. J Am Chem Soc, 2018, 140: 9120-9126

80 Fu C, Liao J, Luo W, et al. Emission of $153 \mu \mathrm{m}$ originating from the lattice site of $\mathrm{Er}^{3+}$ ions incorporated in $\mathrm{TiO}_{2}$ nanocrystals. Opt Lett, 2008, 33: 953

81 Liu Y, Luo W, Li R, et al. Near-infrared luminescence of $\mathrm{Nd}^{3+}$ and $\mathrm{Tm}^{3+}$ ions doped $\mathrm{ZnO}$ nanocrystals. Opt Express, 2009, 17: 97489753

82 Liu Y, Luo W, Li R, et al. Optical properties of $\mathrm{Nd}^{3+}$ ion-doped $\mathrm{ZnO}$ nanocrystals. j nanosci nanotechnol, 2010, 10: 1871-1876

83 Martín-Rodríguez R, Geitenbeek R, Meijerink A. Incorporation and luminescence of $\mathrm{Yb}^{3+}$ in CdSe nanocrystals. J Am Chem Soc, 2013, 135: 13668-13671

84 Duan J, Zhao Y, Yang X, et al. Lanthanide ions doped $\mathrm{CsPbr}_{3}$ 
halides for HTM-free $10.14 \%$-efficiency inorganic perovskite solar cell with an ultrahigh open-circuit voltage of $1.594 \mathrm{~V}$. Adv Energy Mater, 2018, 8: 1802346

85 Mir WJ, Mahor Y, Lohar A, et al. Postsynthesis doping of Mn and $\mathrm{Yb}$ into $\mathrm{CsPbX}_{3}(\mathrm{X}=\mathrm{Cl}, \mathrm{Br}$, or I) perovskite nanocrystals for downconversion emission. Chem Mater, 2018, 30: 8170-8178

86 Naczynski DJ, Sun C, Türkcan S, et al. X-ray-induced shortwave infrared biomedical imaging using rare-earth nanoprobes. Nano Lett, 2015, 15: 96-102

87 Liu L, Wang S, Zhao B, et al. $\mathrm{Er}^{3+}$ sensitized $1530 \mathrm{~nm}$ to $1180 \mathrm{~nm}$ second near-infrared window upconversion nanocrystals for in vivo biosensing. Angew Chem Int Ed, 2018, 57: 7518-7522

88 Cheng X, Ge H, Wei Y, et al. Design for brighter photon upconversion emissions via energy level overlap of lanthanide ions. ACS Nano, 2018, 12: 10992-10999

89 Cheng X, Pan Y, Yuan Z, et al. $\mathrm{Er}^{3+}$ sensitized photon upconversion nanocrystals. Adv Funct Mater, 2018, 28: 1800208

90 Zhydachevskyy Y, Tsiumra V, Baran M, et al. Quantum efficiency of the down-conversion process in $\mathrm{Bi}^{3+}-\mathrm{Yb}^{3+}$ co-doped $\mathrm{Gd}_{2} \mathrm{O}_{3}$. J Lumin, 2018, 196: 169-173

91 Li Y, Zeng S, Hao J. Non-invasive optical guided tumor metastasis/vessel imaging by using lanthanide nanoprobe with enhanced down-shifting emission beyond $1500 \mathrm{~nm}$. ACS Nano, 2019, 13: 248-259

92 Quintanilla M, Zhang Y, Liz-Marzán LM. Subtissue plasmonic heating monitored with $\mathrm{CaF}_{2}: \mathrm{Nd}^{3+}, \mathrm{Y}^{3+}$ nanothermometers in the second biological window. Chem Mater, 2018, 30: 2819-2828

93 Zhou J, Shirahata N, Sun HT, et al. Efficient dual-modal NIR-toNIR emission of rare earth ions co-doped nanocrystals for biological fluorescence imaging. J Phys Chem Lett, 2013, 4: 402-408

94 Li Y, Tang J, Pan DX, et al. A versatile imaging and therapeutic platform based on dual-band luminescent lanthanide nanoparticles toward tumor metastasis inhibition. ACS Nano, 2016, 10: $2766-2773$

$95 \mathrm{Yu}$ XF, Chen LD, Li M, et al. Highly efficient fluorescence of $\mathrm{NdF}_{3} / \mathrm{SiO}_{2}$ core/shell nanoparticles and the applications for in vivo NIR detection. Adv Mater, 2008, 20: 4118-4123

96 Zhang J, Shade CM, Chengelis DA, et al. A strategy to protect and sensitize near-infrared luminescent $\mathrm{Nd}^{3+}$ and $\mathrm{Yb}^{3+}$ : organic tropolonate ligands for the sensitization of $\mathrm{Ln}^{3+}$-doped $\mathrm{NaYF}_{4}$ nanocrystals. J Am Chem Soc, 2007, 129: 14834-14835

97 Ju Q, Luo W, Liu Y, et al. Poly(acrylic acid)-capped lanthanidedoped $\mathrm{BaFCl}$ nanocrystals: synthesis and optical properties. Nanoscale, 2010, 2: 1208-1212

98 Li X, Zhang Q, Ahmad Z, et al. Near-infrared luminescent Ca$\mathrm{TiO}_{3}: \mathrm{Nd}^{3+}$ nanofibers with tunable and trackable drug release kinetics. J Mater Chem B, 2015, 3: 7449-7456

99 Wang P, Fan Y, Lu L, et al. NIR-II nanoprobes in-vivo assembly to improve image-guided surgery for metastatic ovarian cancer. Nat Commun, 2018, 9: 2898

100 Qin QS, Zhang PZ, Sun LD, et al. Ultralow-power near-infrared excited neodymium-doped nanoparticles for long-term in vivo bioimaging. Nanoscale, 2017, 9: 4660-4664

101 Ren F, Ding L, Liu H, et al. Ultra-small nanocluster mediated synthesis of $\mathrm{Nd}^{3+}$-doped core-shell nanocrystals with emission in the second near-infrared window for multimodal imaging of tumor vasculature. Biomaterials, 2018, 175: 30-43

102 Wang R, Li X, Zhou L, et al. Epitaxial seeded growth of rare-earth nanocrystals with efficient $800 \mathrm{~nm}$ near-infrared to $1525 \mathrm{~nm}$ short-wavelength infrared downconversion photoluminescence for in vivo bioimaging. Angew Chem Int Ed, 2014, 53: 1208612090

103 Kamimura M, Omoto A, Chiu HC, et al. Enhanced red upconversion emission of $\mathrm{NaYF}_{4}: \mathrm{Yb}^{3+}, \mathrm{Er}^{3+}, \mathrm{Mn}^{2+}$ nanoparticles for near-infrared-induced photodynamic therapy and fluorescence imaging. Chem Lett, 2017, 46: 1076-1078

104 Zhan Q, Qian J, Liang $\mathrm{H}$, et al. Using $915 \mathrm{~nm}$ laser excited $\mathrm{Tm}^{3+} /$ $\mathrm{Er}^{3+} / \mathrm{Ho}^{3+}$-doped $\mathrm{NaYbF}_{4}$ upconversion nanoparticles for in vitro and deeper in vivo bioimaging without overheating irradiation. ACS Nano, 2011, 5: 3744-3757

105 Li X, Wang R, Zhang F, et al. $\mathrm{Nd}^{3+}$ sensitized up/down converting dual-mode nanomaterials for efficient in-vitro and in-vivo bioimaging excited at $800 \mathrm{~nm}$. Sci Rep, 2013, 3: 3536

106 Smith AM, Mancini MC, Nie S. Second window for in vivo imaging. Nat Nanotechnol, 2009, 4: 710-711

107 Del Rosal B, Ortgies DH, Fernández N, et al. Overcoming autofluorescence: long-lifetime infrared nanoparticles for time-gated in vivo imaging. Adv Mater, 2016, 28: 10188-10193

108 Hoffmann K, Behnke T, Drescher D, et al. Near-infrared-emitting nanoparticles for lifetime-based multiplexed analysis and imaging of living cells. ACS Nano, 2013, 7: 6674-6684

109 Ortgies DH, Tan M, Ximendes EC, et al. Lifetime-encoded infrared-emitting nanoparticles forin vivo multiplexed imaging. ACS Nano, 2018, 12: 4362-4368

110 Fan Y, Wang P, Lu Y, et al. Lifetime-engineered NIR-II nanoparticles unlock multiplexed in vivo imaging. Nat Nanotechnol, 2018, 13: 941-946

111 Tu D, Liu L, Ju Q, et al. Time-resolved FRET biosensor based on amine-functionalized lanthanide-doped $\mathrm{NaYF}_{4}$ nanocrystals. Angew Chem Int Ed, 2011, 50: 6306-6310

112 Liu Y, Zhou S, Tu D, et al. Amine-functionalized lanthanidedoped zirconia nanoparticles: optical spectroscopy, time-resolved fluorescence resonance energy transfer biodetection, and targeted imaging. J Am Chem Soc, 2012, 134: 15083-15090

113 Zheng W, Zhou S, Chen Z, et al. Sub-10 nm lanthanide-doped $\mathrm{CaF}_{2}$ nanoprobes for time-resolved luminescent biodetection. Angew Chem Int Ed, 2013, 52: 6671-6676

114 Huang P, Zheng W, Zhou S, et al. Lanthanide-doped $\mathrm{LiLuF}_{4}$ upconversion nanoprobes for the detection of disease biomarkers. Angew Chem Int Ed, 2014, 53: 1252-1257

115 Zhou S, Zheng W, Chen Z, et al. Dissolution-enhanced luminescent bioassay based on inorganic lanthanide nanoparticles. Angew Chem Int Ed, 2014, 108: 12498-12502

116 Xu J, Zhou S, Tu D, et al. Sub-5 nm lanthanide-doped lutetium oxyfluoride nanoprobes for ultrasensitive detection of prostate specific antigen. Chem Sci, 2016, 7: 2572-2578

117 Tao Z, Dang X, Huang X, et al. Early tumor detection afforded by in vivo imaging of near-infrared II fluorescence. Biomaterials, 2017, 134: 202-215

118 Ximendes EC, Santos WQ, Rocha U, et al. Unveiling in vivo subcutaneous thermal dynamics by infrared luminescent nanothermometers. Nano Lett, 2016, 16: 1695-1703

119 Cerón EN, Ortgies DH, Del Rosal B, et al. Hybrid nanostructures for high-sensitivity luminescence nanothermometry in the second biological window. Adv Mater, 2015, 27: 4781-4787

120 Kolesnikov IE, Golyeva EV, Kalinichev AA, et al. $\mathrm{Nd}^{3+}$ single doped $\mathrm{YVO}_{4}$ nanoparticles for sub-tissue heating and thermal sensing in the second biological window. Sensor Actuat B-Chem, 2017, 243: 338-345

121 Balabhadra S, Debasu ML, Brites CDS, et al. Implementing lu- 
minescence thermometry at $1.3 \mu \mathrm{m}$ using $(\mathrm{GdNd})_{2} \mathrm{O}_{3}$ nanoparticles. J Lumin, 2016, 180: 25-30

122 Hernández-Rodríguez MA, Lozano-Gorrín AD, Martín IR, et al. Comparison of the sensitivity as optical temperature sensor of nano-perovskite doped with $\mathrm{Nd}^{3+}$ ions in the first and second biological windows. Sensor Actuat B-Chem, 2018, 255: 970-976

123 Marciniak L, Bednarkiewicz A. Nanocrystalline NIR-to-NIR luminescent thermometer based on $\mathrm{Cr}^{3+}, \mathrm{Yb}^{3+}$ emission. Sensor Actuat B-Chem, 2017, 243: 388-393

$124 \mathrm{Xu} \mathrm{M}$, Zou X, Su Q, et al. Ratiometric nanothermometer in vivo based on triplet sensitized upconversion. Nat Commun, 2018, 9: 2698

125 Brites CDS, Lima PP, Silva NJO, et al. A luminescent molecular thermometer for long-term absolute temperature measurements at the nanoscale. Adv Mater, 2010, 22: 4499-4504

126 Maestro LM, Haro-González P, Iglesias-de la Cruz MC, et al. Fluorescent nanothermometers provide controlled plasmonicmediated intracellular hyperthermia. Nanomedicine, 2013, 8: 379-388

127 Okabe K, Inada $\mathrm{N}$, Gota $\mathrm{C}$, et al. Intracellular temperature mapping with a fluorescent polymeric thermometer and fluorescence lifetime imaging microscopy. Nat Commun, 2012, 3: 705

128 Wawrzynczyk D, Bednarkiewicz A, Nyk M, et al. Neodymium (III) doped fluoride nanoparticles as non-contact optical temperature sensors. Nanoscale, 2012, 4: 6959-6961

129 Benayas A, del Rosal B, Pérez-Delgado A, et al. Nd:YAG nearinfrared luminescent nanothermometers. Adv Opt Mater, 2015, 3: 687-694

Acknowledgements This work was supported by the Strategic Priority Research Program of the CAS (XDB20000000), the National Natural Science Foundation of China $(21771185,11704380,51672272,21804134$ and U1805252), the CAS/SAFEA International Partnership Program for Creative Research Teams, and the Natural Science Foundation of Fujian Province (201710018).

Author contributions $\mathrm{Yu} \mathrm{S,Tu} \mathrm{D} \mathrm{and} \mathrm{Chen} \mathrm{X} \mathrm{conceived} \mathrm{and} \mathrm{wrote}$ the manuscript and designed the figures. Lian $\mathrm{W}$ and $\mathrm{Xu}$ J prepared the materials of bioapplications. All authors contributed to the general discussion and revision of the manuscript.

Conflict of interest The authors declare no conflict of interest.

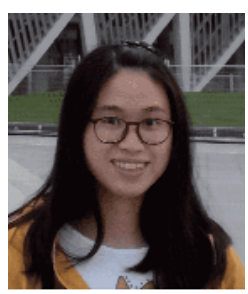

Shaohua Yu earned her BSc degree from Fuzhou University (2015). She is currently a PhD student in condensed matter physics in the University of Chinese Academy of Sciences (UCAS). In September 2015, she joined Prof. Xueyuan Chen's group in Fujian Institute of Research on the Structure of Matter (FJIRSM). Her current research focuses on the controlled synthesis and optical spectroscopy of inorganic luminescent nanomaterials.

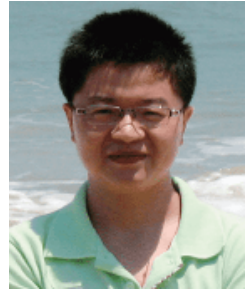

Datao Tu earned his BSc degree (2006) from Wuhan University of Technology. He received his $\mathrm{PhD}$ degree (2011) in materials physics and chemistry from FJIRSM, Chinese Academy of Sciences. He joined Prof. Xueyuan Chen's group as a research assistant professor in July 2011 and was promoted to research associate professor in 2014. His research focuses on the chemical synthesis, optical spectroscopy and biodetection of lanthanide-doped nanoprobes.

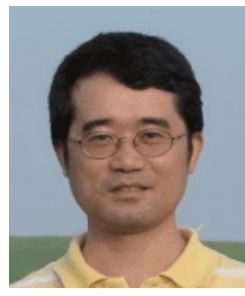

Xueyuan Chen earned his BSc degree from the University of Science and Technology of China (1993) and his PhD degree from FJIRSM, Chinese Academy of Sciences (1998). From 2001 to 2005, he was a postdoctoral research associate at the Chemistry Division of Argonne National Laboratory, U.S. Department of Energy, where he studied the photophysics and photochemistry of heavy elements. In 2005, he joined the faculty at FJIRSM, where he is currently professor and group leader in Material Chemistry and Physics.

His research focuses on the chemistry, optical spectroscopy and bioapplications of lanthanide-doped luminescent nanomaterials.

\section{稀土掺杂近红外二区发光纳米探针及其生物应用}

余少桦 ${ }^{1,2}$, 涂大涛 $^{1 *}$, 廉纬 ${ }^{1,3}$, 徐金 $^{1}$, 陈学元 ${ }^{1,2,3^{*}}$

摘要 近红外二区 $(1000-1700 \mathrm{~nm})$ 荧光纳米探针可以显著降低穿 透组织时的光散射和自苂光效应的影响, 从而提高探测深度以及 成像分辨率. 目前已报道的近红外二区生物探针主要基于有机苂 光团、碳纳米管、量子点以及共轭聚合物. 稀土离子掺杂纳米晶 因其优异的发光性质, 被认为是一类极具发展潜力的生物探针. 本 文从设计高效近红外二区发光的稀土掺杂纳米材料的角度出发, 主要介绍了此类稀土纳米探针的基质选择、阳离子掺杂和表面修 饰等设计策略的研究进展, 及其在无背景生物成像、高灵敏生物 检测和温度探测等领域的最新应用. 此外, 还展望了此类苂光纳米 探针面临的挑战以及未来发展趋势. 